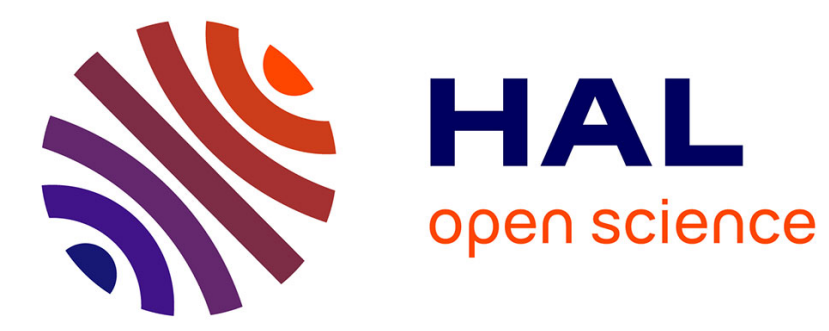

\title{
Rupture characteristics of major and great $(\geq 7.0)$ megathrust earthquakes from 1990 to 2015: 1. Source parameter scaling relationships
}

\author{
Lingling Ye, Thorne Lay, Hiroo Kanamori, Luis Rivera
}

\section{- To cite this version:}

Lingling Ye, Thorne Lay, Hiroo Kanamori, Luis Rivera. Rupture characteristics of major and great ( $\geq 7.0$ ) megathrust earthquakes from 1990 to 2015: 1. Source parameter scaling relationships. Journal of Geophysical Research: Solid Earth, 2016, 121 (2), pp.826-844. 10.1002/2015JB012426 . hal02497897

\section{HAL Id: hal-02497897 \\ https://hal.science/hal-02497897}

Submitted on 9 Sep 2021

HAL is a multi-disciplinary open access archive for the deposit and dissemination of scientific research documents, whether they are published or not. The documents may come from teaching and research institutions in France or abroad, or from public or private research centers.
L'archive ouverte pluridisciplinaire HAL, est destinée au dépôt et à la diffusion de documents scientifiques de niveau recherche, publiés ou non, émanant des établissements d'enseignement et de recherche français ou étrangers, des laboratoires publics ou privés. 


\section{Journal of Geophysical Research: Solid Earth}

\section{RESEARCH ARTICLE \\ 10.1002/2015JB012426 \\ This article is a companion to Ye et al. \\ Rupture characteristics of major and great $\left(M_{w} \geq 7.0\right)$ megathrust earthquakes from 1990 to 2015: 1. Source parameter scaling relationships} [2016] doi:10.1002/2015JB012427.

Key Points:

- Source parameters for 114 major and great megathrust ruptures are determined and analyzed

- The product of stress drop and cube of rupture velocity is stable for finitefault inversions

- Rupture geometrical parameters have large variability and must be determined to understand scaling

Supporting Information:

- Figures S1-S6, Tables S1 and S2, and Texts S1 and S2

- Text $\mathrm{S1}$ figures

- Text S2 figures

Correspondence to:

T. Lay,

tlay@ucsc.edu

Citation:

Ye, L., T. Lay, H. Kanamori, and L. Rivera (2016), Rupture characteristics of major and great $\left(M_{w} \geq 7.0\right)$ megathrust earthquakes from 1990 to 2015: 1 . Source parameter scaling relationships, J. Geophys. Res. Solid Earth, 121, 826-844, doi:10.1002/2015JB012426.

Received 6 AUG 2015 Accepted 6 JAN 2016

Accepted article online 20 JAN 2016

Published online 18 FEB 2016

(c)2016. American Geophysical Union. All Rights Reserved.

\author{
Lingling Ye ${ }^{1,2}$, Thorne Lay ${ }^{1}$, Hiroo Kanamori ${ }^{2}$, and Luis Rivera ${ }^{3}$ \\ ${ }^{1}$ Department of Earth and Planetary Sciences, University of California, Santa Cruz, California, USA, ${ }^{2}$ Seismological \\ Laboratory, California Institute of Technology, Pasadena, California, USA, ${ }^{3}$ Institut de Physique du Globe de Strasbourg, \\ Université de Strasbourg/CNRS, Strasbourg, France
}

Abstract Source parameter scaling for major and great thrust-faulting events on circum-Pacific megathrusts is examined using uniformly processed finite-fault inversions and radiated energy estimates for $114 M_{w} \geq 7.0$ earthquakes. To address the limited resolution of source spatial extent and rupture expansion velocity $\left(V_{r}\right)$ from teleseismic observations, the events are subdivided into either group 1 (18 events) having independent constraints on $V_{r}$ from prior studies or group 2 (96 events) lacking independent $V_{r}$ constraints. For group 2 , finite-fault inversions with $V_{r}=2.0,2.5$, and $3.0 \mathrm{~km} / \mathrm{s}$ are performed. The product $V_{r}^{3} \Delta \sigma_{E}$, with stress drop $\Delta \sigma_{E}$ calculated for the slip distribution in the inverted finite-fault models, is very stable for each event across the suite of models considered. It has little trend with $M_{w}$, although there is a baseline shift to low values for large tsunami earthquakes. Source centroid time $\left(T_{c}\right)$ and duration $\left(T_{d}\right)$, measured from the finite-fault moment rate functions vary systematically with the cube root of seismic moment $\left(M_{0}\right)$, independent of assumed $V_{r}$. There is no strong dependence on magnitude or $V_{r}$ for moment-scaled radiated energy $\left(E_{R} / M_{0}\right)$ or apparent stress $\left(\sigma_{a}\right) . \Delta \sigma_{E}$ averages $\sim 4 \mathrm{MPa}$, with direct trade-off between $V_{r}$ and estimated stress drop but little dependence on $M_{w}$. Similar behavior is found for radiation efficiency $\left(\eta_{R}\right)$. We use $V_{r}^{3} \Delta \sigma_{E}$ and $T_{c} / M_{0}{ }^{1 / 3}$ to explore variation of stress drop, $V_{r}$ and radiation efficiency, along with finite-source geometrical factors. Radiation efficiency tends to decrease with average slip for these very large events, and fracture energy increases steadily with slip.

\section{Introduction}

How earthquake source parameters vary with event size and the extent to which there may be deterministic characteristics for all earthquake failures have been the subjects of investigations for several decades [e.g., Aki, 1967; Kanamori and Anderson, 1975; Ohnaka, 2003]. Earthquake source parameter scaling is fundamental for understanding mechanics of earthquake ruptures. Many studies have sought to measure fundamental rupture parameters, such as source duration, static stress drop, radiated seismic energy, apparent stress, dynamic stress drop, and rupture area from seismic observations, and to establish their scaling relationships with seismic moment. Diverse results and implications have been found for different earthquake magnitude ranges and tectonic environments [e.g., Venkataraman and Kanamori, 2004] or using different seismological methods.

There have been numerous estimates of the static stress drop or apparent stress for minor to moderate $\left(M_{w}<\sim 6\right)$ earthquakes by fitting average source amplitude spectra with parameterized point source representations [e.g., Abercrombie, 1995; Choy et al., 2006; Shearer et al., 2006; Allmann and Shearer, 2009] that involve a corner frequency $\left(f_{c}\right)$ and high-frequency $(\omega)$ spectral decay rate (often assumed to be $\omega^{-2}$ ) [e.g., Brune, 1970; Madariaga, 1976]. Relatively little magnitude dependence of estimated static stress drop inferred from such spectral modeling is apparent for event sizes varying over several orders of magnitude [e.g., Allmann and Shearer, 2009], although there is a large scatter in stress drop estimates. Some studies report systematically increasing apparent stress estimates as earthquake size increases [e.g., Abercrombie, 1995; Kanamori et al., 1993; Abercrombie and Rice, 2005; Walter et al., 2006], while others find no dependence of apparent stress on seismic moment [e.g., McGarr, 1999; Ide and Beroza, 2001; Pérez-Campos and Beroza, 2001; Ide et al., 2003; Baltay et al., 2014]. Bandwidth limitations [Ide and Beroza, 2001], attenuation uncertainty [Ide, 2002; Baltay et al., 2011], and variability of stress drop estimates due to errors in corner frequency measurement [Prieto et al., 2007] may all have contributed to the discrepancies. Walter et al. [2006] provided a comprehensive summary of the debate over whether there is significant scaling of seismic energy with moment. 


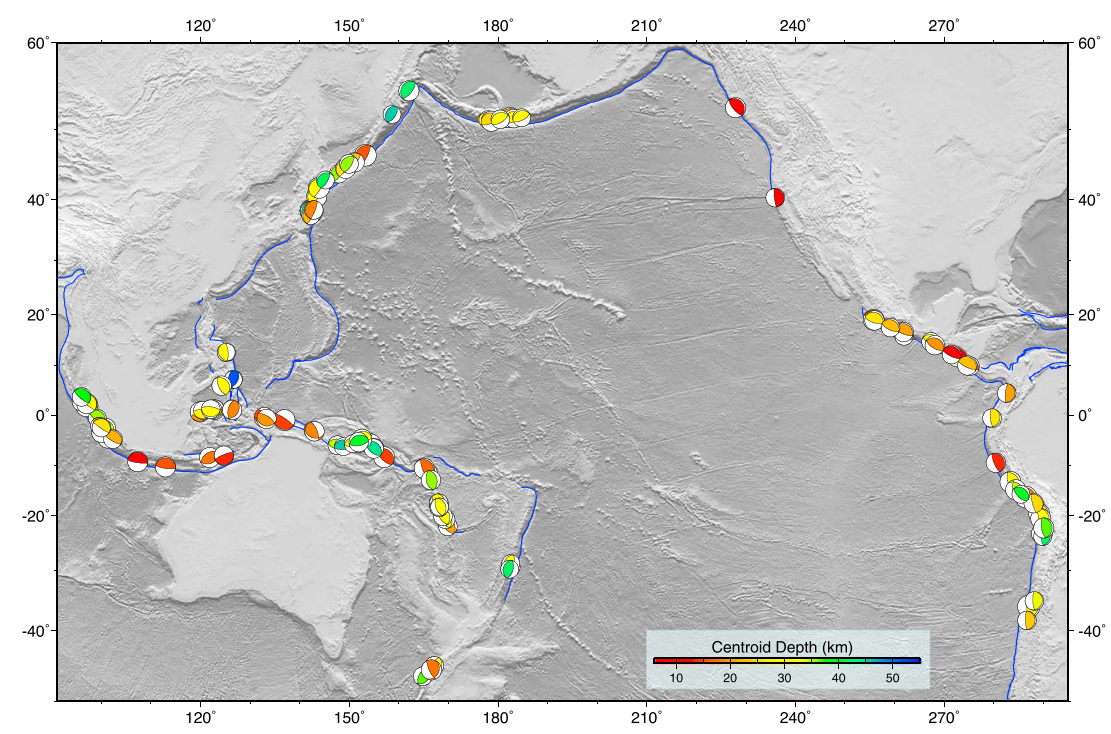

Figure 1. Epicentral locations indicated by best double-couple focal mechanisms from GCMT catalog for the 114 major and great $\left(M_{w} \geq 7\right)$ megathrust earthquakes from 1990 to 2015 analyzed in this study. Focal mechanism radius is scaled proportional to $M_{w}$ and color indicates GCMT centroid depth. All major and great interplate thrust events for which reliable source parameter estimates could be made are included.

For events with magnitude larger than $\sim 6$, it is unclear that earthquakes can be treated as point sources with simplified spectral amplitude methods being used to estimate source parameters. Even for strong earthquakes $\left(M_{w} 6.0-6.9\right)$, point source moment rate functions show significant variability [e.g., Bilek and Lay, 2000] that is not well captured by average spectral amplitude analysis alone (i.e., ignoring phase information). Determining the stress evolution over space and time during the rupture process is required for many source parameters to be meaningfully estimated (this is likely also true of smaller sources, but there are observational limits for globally determining finite-source properties for small events).

Over the past 25 years the occurrence of many major and great global earthquakes, along with rapid advances in seismic and geodetic data collection and analysis, has reinforced the tremendous range of complexity of large earthquakes [Kanamori, 2014; Lay, 2015]. The source complexity of major and great earthquakes $\left(M_{w} \geq 7\right)$ certainly cannot be well captured by point source spectral amplitude averages. To account for the finiteness of large earthquakes, we investigate scaling relations for megathrust events obtained from finite-fault inversions along with short-period spectral stacking and radiated energy estimates.

We document the primary source characteristics for all major and great $\left(M_{w} \geq 7\right)$ subduction zone interplate earthquakes from 1990 to 2015 (Figure 1) using global broadband body wave observations (for frequencies below $1 \mathrm{~Hz}$ ). There are systematic differences in some source characteristics between interplate and intraplate events [e.g., Venkataraman and Kanamori, 2004; Allmann and Shearer, 2009; Ye et al., 1970; Kanamori, 2014], so this study does not span the entire range of shallow major earthquake behavior. Given the intrinsic limitations of estimating source parameters from teleseismic body wave analyses associated with limited slowness coverage, and uncertainties in attenuation and model parameterization, we will not strive for quantitative rupture mechanics interpretations but focus on evaluation of basic scaling relations. We consider a suite of rupture models for each event, computed for varying rupture expansion velocity, $V_{r}$. We then discuss scaling relationships for the measured source parameters: the product $V_{r}^{3} \Delta \sigma_{E}$, with stress drop $\Delta \sigma_{E}$ calculated for the slip distribution in the inverted finite-fault models, source centroid time and total duration, moment-scaled radiated energy, and apparent stress. We explore the variability in geometric terms for the megathrust ruptures, along with variations in source models for ranges of stress drop and radiation efficiency. Combining our results with previous work [Abercrombie and Rice, 2005], we investigate radiation efficiency and fracture energy behavior over a wide range of earthquake average slip. In a companion paper [Ye et al., 2016: henceforth labeled Paper 2], we explore these source parameter variations with tectonic environment and source depth. 


\section{Teleseismic Finite-Fault Inversions}

In order to focus on rupture characteristics along plate boundary megathrust faults we select events using criteria that include having a shallow-dipping thrust fault focal mechanism from the Global Centroid Moment Tensor (GCMT) catalog (http://www.globalcmt.org/CMTsearch.html), location near the interplate contact, and source depth less than $60 \mathrm{~km}$. We consider all $M_{w} \geq 7$ events from the GCMT and U.S. Geological Survey (USGS)/National Earthquake Information Center (NEIC) catalogs (http://earthquake.usgs.gov/earthquakes) from 1990 to July 2015. This spans the time interval when substantial numbers of global digital broadband seismograms are available for each event from the Incorporated Research Institutions for Seismology data center (http://www.iris.edu/wilber3/find_event). Several events meeting the above selection criteria, but having very limited azimuthal coverage of data (mainly events in the early 1990s), low signal-to-noise ratios (typically as a result of being preceded by another large event), or unusually strong water/sediment reverberations that we were unable to model satisfactorily, are excluded. Several additional likely intraplate thrust events are also eliminated. The 26 December $2004 M_{w} 9.2$ Sumatra earthquake is excluded from the finite-fault characterization because the extremely long source duration prevents us from isolating teleseismic $P$ waves and $S H$ waves for the finite-source inversion method used in this study. The final data set is comprised of 114 events globally distributed as shown in Figure 1.

For each earthquake we obtain systematic estimates of the slip distribution, moment rate function, source centroid depth and time, total source duration, static stress drop, broadband source spectrum, radiated seismic energy, apparent stress, and radiation efficiency. The variations of these source characteristics with seismic moment are then examined for scaling behavior. The precision with which these source parameters can be estimated using only teleseismic observations varies with event location (affects data distribution), date of occurrence (affects number of available data), and required information for each measurement (level of dependence on velocity structure, faulting parameterization, etc.). Some source attributes are relatively robustly determined by teleseismic data (moment rate function and centroid time), whereas measures that depend on estimates of rupture dimension (static stress drop and radiation efficiency), or dynamic source properties (radiated energy and apparent stress) are strongly affected by modeling parameters. Errors associated with the assumptions are very hard to quantify, as they propagate into the estimates in complex ways. Some recent analysis [e.g., Gallovič et al., 2015] demonstrates trade-off between spatial and temporal smoothing in resolving the kinematic slip distribution and evolution during the rupture process and additional effects of parameterization and 3-D structure in the Green's functions. For a global study, we cannot realistically address 3-D source structure effects and it is most useful to instead adopt relatively uniform parameterization of faulting. As a result, we will evaluate uncertainties qualitatively, conveying the level of confidence appropriate for each type of measurement, but we do not attempt to quantify model error effects rigorously, as it is unrealistic to do so and the earthquakes appear to have large intrinsic variations that are real.

For each of the 114 earthquakes identified as a large megathrust rupture we perform a finite-fault inversion using ground displacements in the passband $0.005-0.9 \mathrm{~Hz}$ for teleseismic $P$ waves and in a few cases also $\mathrm{SH}$ waves. We use the least squares kinematic inversion method with positivity constraint for constant rupture front expansion velocity $\left(V_{r}\right)$, specified planar fault geometry, and subfault source time functions parameterized by several overlapping triangles. The inversion code was written by Kikuchi and Kanamori [1991], is archived at http://www.eri.u-tokyo.ac.jp/ETAL/KIKUCHI/, and uses a method similar to that developed by Hartzell and Heaton [1983]. We modify the teleseismic body wave inversion code to include a constraint to minimize the difference of the inverted total seismic moment from the long-period seismic moment estimate (GCMT). This stabilizes the inversion process and allows flexibility in the number of triangles assigned for each subfault and use of subfaults with relatively small grid size, as needed for the smaller events. For each event, we adjust the subfault source time functions to give a stable rupture pattern with limited model parameters. The hypocentral depth $\left(h_{0}\right)$ is typically set as the value from the USGS-NEIC bulletin, but this is perturbed when it appears to be inaccurate based on waveform misfits or overall inconsistency with long-period centroid depth constraints. The fault geometry is generally specified with strike and dip from the GCMT best double couple solution, unless the body wave modeling motivated perturbations from those solutions. The source region crustal model is usually obtained from Crust 2.0 [Bassin et al., 2000], with 1-D layered structure Green's functions being computed using a propagator matrix method [Bouchon, 1981]. 


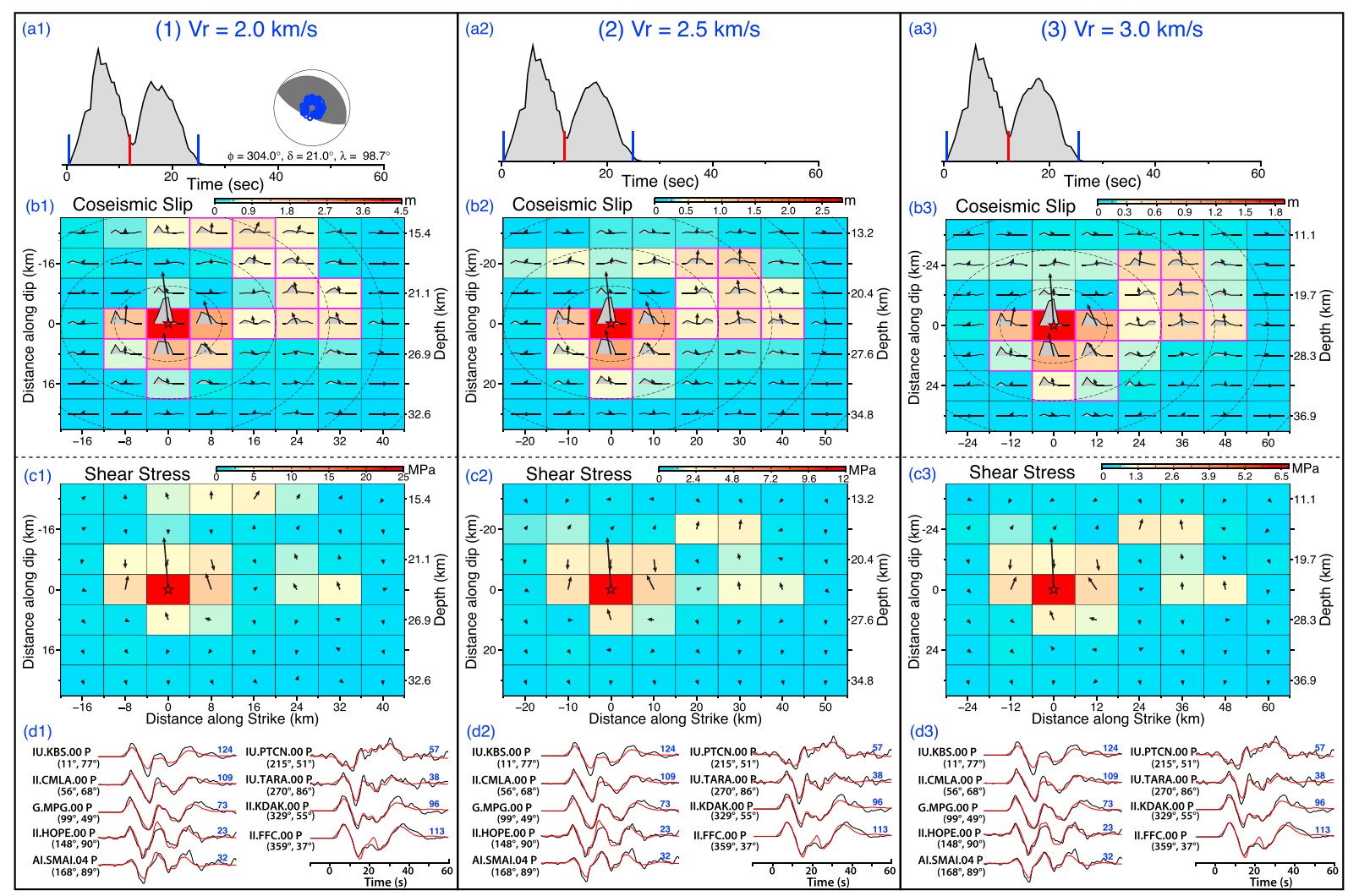

Figure 2. Example of finite-fault inversions using different rupture speed, $V_{r}$, with subfault grid-spacing proportional to $V_{r}$ for the 18 April 2014 Guerrero, Mexico event $\left(M_{w}\right.$ 7.3). Solution parameters are listed in Table 1. (a) The moment rate function for each inversion is shown. Blue ticks indicate the time span used to determine total duration, Td, and the centroid time, $T_{c}$, is indicated by the red tick. The average focal mechanism with double couple strike $(\phi)$, dip $(\delta)$, and rake $(\lambda)$ is almost identical for each inversion. (b) The subfault grid, with average subfault slip direction and magnitude indicated by the vectors, and slip magnitude color coded. Dashed circles indicated rupture front position in $5 \mathrm{~s}$ intervals. (c) The average stress vector at the center of each subfault used to compute stress drop for the variable slip solution. (d) Comparisons of sampled observed (black) and predicted (red) $P$ waveforms are shown. Below each station name the azimuth and distance of the station relative to the source is indicated. The peak-to-peak amplitude of the data trace in microns is shown in blue; each waveform is normalized to uniform amplitude. All waveforms used in the finite-fault inversion for this event are shown in Text S2 Figures.

Given the limited resolution of source finiteness from teleseismic body wave observations, in order to best constrain the rupture expansion velocity $\left(V_{r}\right)$ we classified the 114 events into two groups. Group 1 (18 events) has independent constraints from prior detailed rupture analyses that used similar basic rupture model formulation as we use here and we adopt the preferred values of $V_{r}$ from those studies. Group 2 (96 events), for which independent constraints are lacking, is analyzed with a suite of models for each event with different $V_{r}$. For each earthquake in group 1 (Table S1 in the supporting information), the rupture model parameterization and dimensions from the literature (citations in Table S1) are used in new inversions, applying the same seismic moment constraint and spatial smoothing as used for all other events. The final rupture models and waveform fits for each event in this group are presented in Text S1.

For each earthquake in group 2 (Table S2), three finite-fault inversions with $V_{r}=2.0 \mathrm{~km} / \mathrm{s}, 2.5 \mathrm{~km} / \mathrm{s}$, and $3.0 \mathrm{~km} / \mathrm{s}$ and proportionally scaled grid spacing of $8 \mathrm{~km}, 10 \mathrm{~km}$, and $12 \mathrm{~km}$, respectively, have been performed. The final rupture models and waveform fits for $V_{r}=2.5 \mathrm{~km} / \mathrm{s}$ are all presented in Text S2. As a representative example, Figure 2 shows the results for finite-fault models with $V_{r}=2.0 \mathrm{~km} / \mathrm{s}, V_{r} 2.5 \mathrm{~km} / \mathrm{s}$, and $V_{r} 3.0 \mathrm{~km} / \mathrm{s}$ for the 18 April $2014 M_{w} 7.2$ Guerrero earthquake. For this event, and for all others, we determine the overall fault-perpendicular moment rate function from the combined source time functions for each subfault (Figures 2a1, 2a2, and 2a3), the average focal mechanism (Figure 2a1), the variable rake space-time slip distribution with subfault source time functions (Figures $2 \mathrm{~b} 1,2 \mathrm{~b} 3$, and $2 \mathrm{~b} 3$ ) and the shear stress distribution (Figures $2 \mathrm{c} 1,2 \mathrm{c} 3$, and 2c3). The computation of shear stress distribution for the inverted slip models uses the analytic methods developed by Mansinha and Smylie [1971] and Okada [1992], assuming a homogeneous half-space and computing the shear stress at the center of each subfault. Only a subset of the observed and 
Table 1. Source Parameters for the Models in Figure 2 for the 18 April 2014 Guerrero, Mexico Event $\left(M_{w}\right.$ 7.3)

\begin{tabular}{|c|c|c|c|c|c|c|c|c|c|c|c|c|}
\hline $\operatorname{Vr}(\mathrm{km} / \mathrm{s})$ & Variance & $M_{0}(\mathrm{~N} \mathrm{~m})$ & $T_{d}(\mathrm{~s})$ & $T_{c}(\mathrm{~s})$ & $H_{0}(\mathrm{~km})$ & $H_{c}(\mathrm{~km})$ & Rake (deg) & Grid Size (km) & $A_{\text {eff }}^{\mathrm{a}}\left(\mathrm{km}^{2}\right)$ & $\Delta \sigma_{E}(\mathrm{MPa})$ & $D^{\mathrm{a}}(\mathrm{m})$ & $V r^{3} \Delta \sigma_{E}\left(\mathrm{~km}^{3} \cdot \mathrm{MPa}\right)$ \\
\hline 2.0 & 0.127 & $9.43 \times 10^{19}$ & 24.5 & 12.0 & 24.0 & 22.8 & 98.7 & 8.0 & 1088 & 6.36 & 1.27 & 50.88 \\
\hline 2.5 & 0.120 & $9.41 \times 10^{19}$ & 24.5 & 12.0 & 24.0 & 22.9 & 98.7 & 10.0 & 1800 & 2.94 & 0.80 & 45.94 \\
\hline 3.0 & 0.118 & $9.41 \times 10^{19}$ & 25.0 & 12.2 & 24.0 & 22.8 & 98.8 & 12.0 & 2736 & 1.63 & 0.53 & 44.01 \\
\hline
\end{tabular}

${ }^{\mathrm{a}}$ The trimming factors of $0.14,0.12$, and 0.12 , which provide circular rupture models with uniform average slip that give stress drops that match $\Delta \sigma_{E}$ calculations, are used in estimating the effective rupture area and the corresponding average slip for slip models with $v_{r} 2.0,2.5$, and $3.0 \mathrm{~km} / \mathrm{s}$, respectively.

modeled waveforms are shown in Figures $2 \mathrm{~d} 1-2 \mathrm{~d} 3$; the entire data sets are displayed in Text S2 for this event and for all others. About $90 \%$ of the $P$ waveform power is accounted for by the source models shown in Figure 2. The moment rate functions are very similar between the models, and the spatial pattern of slip is similar. However, the spatial dimensions, the amount of slip, and the static stress drop vary significantly with the rupture expansion velocity, $V_{r}$. This behavior with $V_{r}$ applies to all solutions. The goodness of waveform fits varies little with $V_{r}$, and optimization of the source model based on waveform misfit is not a well-constrained procedure. This is, in part, due to the large number of parameters in the models and the intrinsically variable degrees of freedom for fitting the data from using variable grid dimensions and multiple subfault subevents. It is misleading to hold all parameters fixed and to optimize any one parameter, such as $V_{r}$, based on waveform fits when all the parameters are coupled and not uniquely resolved independently. As a result, we treat the range of models as a sampling of viable models for a reasonable suite of key kinematic parameters.

For these finite-fault rupture solutions, we computed the seismic moment $\left(M_{0}\right)$, rupture centroid depth estimated from the average depth of the slip distribution $\left(H_{c}\right)$, averages of source rigidity $(\mu), P$ wave velocity $\left(V_{p}\right)$, $S$ wave velocity $\left(V_{s}\right)$, and density $(\rho)$ weighted by the slip distribution, source centroid time $\left(T_{c}\right)$ and total duration $\left(T_{d}\right)$ measured from the moment rate function as the time interval spanned by reliably resolved source radiation, effective rupture areas and corresponding average slip for specific trimming factors (discussed in section 3.2), and average static stress drop $\left(\Delta \sigma_{E}\right)$ weighted by the slip distribution following the method of Noda et al. [2013]. Table 1 shows these source parameters for the three slip models for the 18 April 2014 Guerrero Mexico event. For all events the corresponding values are presented in the supporting information Tables S1 and S2 for group 1 events and group 2 events, respectively. In the following discussion, the values for source parameters such as seismic moment, average centroid depth, and source duration that have little dependence on $V_{r}$ are given for the results of slip models with $V_{r} 2.5 \mathrm{~km} / \mathrm{s}$ for group 2 events. The total duration measure is sometimes subjective, as it is influenced by the adequacy of the Green's functions for accounting for water reverberations and late scattered waves. We obtained the $T_{d}$ estimates by eye ignoring very weak tails in the moment rate functions, as these may be artifacts due to inaccurate modeling of the coda. The nature of inversions with moment rate function positivity constraint is such that these measurements may be biased a bit long, but our application of a penalty function relative to the long-period seismic moment suppresses instability.

Teleseismic body waves for major and great events generally do not tightly constrain seismic moment due to bandwidth limitations and dependence on the model parameterization. By imposing an a priori constraint on the seismic moment, the inverted moment estimates are in general comparable with GCMT seismic moment estimates obtained by inversion of long-period ( 40-350 s) seismic waves, with discrepancies less than $20 \%$ (Figure 3a). The systematically larger seismic moment estimates from the finite-fault inversions for earthquakes with magnitude $<7.4$ may be the result of differences in the source velocity models (GCMT uses preliminary reference Earth model (PREM), while local crustal models are used in the finite-fault inversions) or differences in source centroid depth for spatially concentrated sources, along with effects of the positivity constraint on poorly resolved, low moment regions of the compact rupture models for smaller events. These effects appear to be insignificant for larger ruptures.

The slip-weighted average source depths and centroid times from finite-fault inversion are generally consistent with values from the GCMT catalog for all magnitudes (Figures 3b and 3c), although there are a few outliers. We also find general consistency with corresponding values from $W$ phase inversions [Duputel et al., 2013]. Most estimates are within $\pm 10 \mathrm{~km}$ for depths and $\pm 5 \mathrm{~s}$ for centroid time. Some of the variability in depth estimates stems from using localized crustal structures for the finite-fault inversions in contrast to the PREM structure uniformly used in the long-period inversions. 

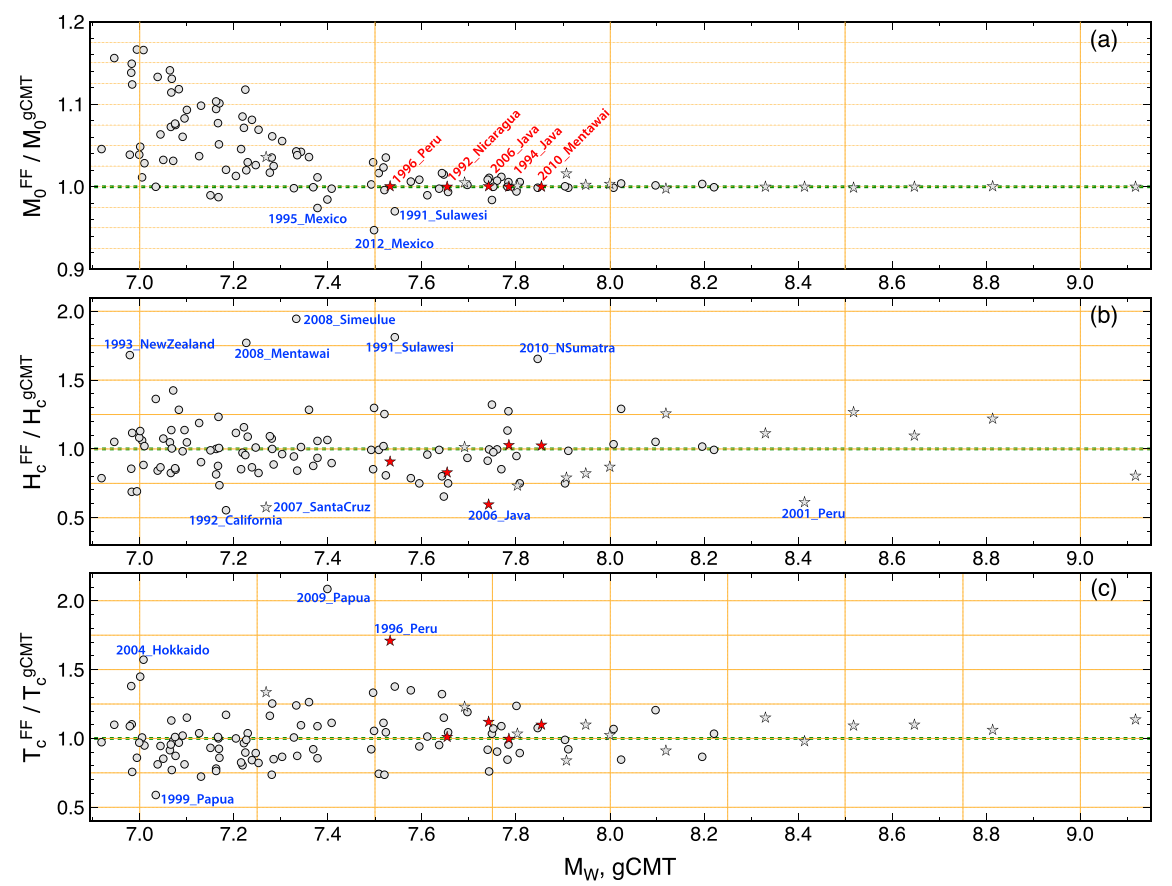

Figure 3. Ratios of finite-fault inversion (FF) estimates with $V_{r}=2.5 \mathrm{~km} / \mathrm{s}$ (circles) or independent specific $V_{r}$ (stars) to GCMT estimates for (a) seismic moment, (b) centroid depth $H_{c}$ and (c) centroid time $T_{c}$. Similar behavior is found for the ratios for finite-fault inversions with $V_{r}$ of $2.0 \mathrm{~km} / \mathrm{s}$ or $3.0 \mathrm{~km} / \mathrm{s}$. Events with outlying ratios are labeled. Five notable tsunami earthquakes, 1992 Nicaragua, 1994 Java, 1996 Peru, 2006 Java, and 2010 Mentawai are highlighted with red labels and stars.

As shown in Table 1, there is a strong trade-off between the $V_{r}$ and the stress drop, $\Delta \sigma_{E}$. This is the wellknown difficulty in constraining $\Delta \sigma_{E}$ with slip inversion [e.g., Noda et al., 2013]. The trade-off is generally given by $\Delta \sigma_{E} \propto V_{r}^{-3}$. Thus, the product $V_{r}^{3} \Delta \sigma_{E}$ is very stable for the inverted slip models for each event with $V_{r}$ ranging from $2 \mathrm{~km} / \mathrm{s}$ to $3 \mathrm{~km} / \mathrm{s}$ as clearly shown in the last column of Table 1 . This is true for all other events, as shown in Figure 4. In other words, slip inversion can constrain $V_{r}^{3} \Delta \sigma_{E}$ tightly despite the strong trade-off between $V_{r}$ and $\Delta \sigma_{E}$.

Figure 4 clearly distinguishes five well-known tsunami earthquakes that have unusually large tsunami excitation relative to their short-period seismic magnitudes [Polet and Kanamori, 2009] from the other events, reflecting the significant difference in the rupture physics. Generally, tsunami earthquakes have been recognized to have

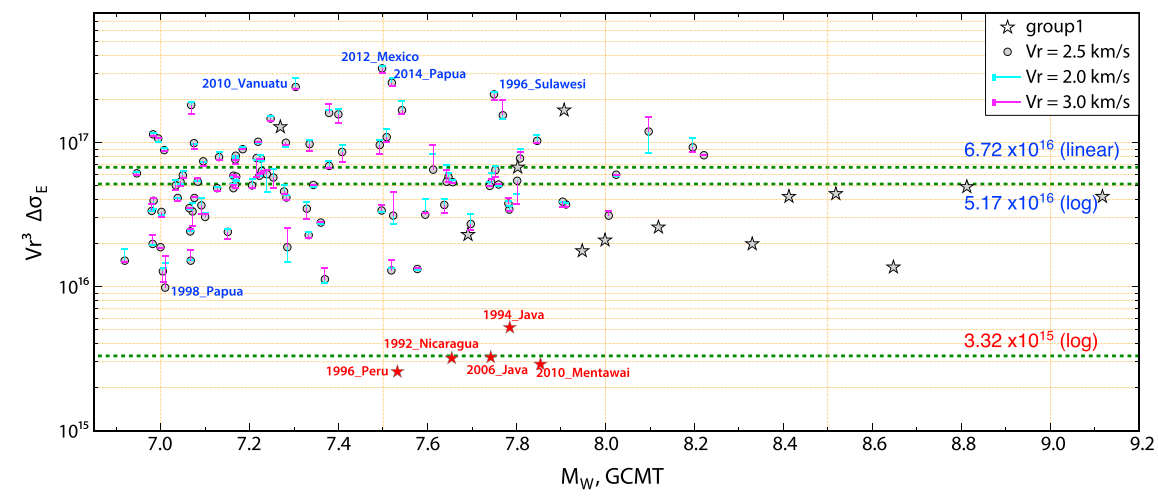

Figure 4. The products of $V r^{3} \Delta \sigma_{E}$ from the finite fault slip models for $V_{r}=2.5 \mathrm{~km} / \mathrm{s}$ (circles), $2.0 \mathrm{~km} / \mathrm{s}$ (cyan bars), and $3.0 \mathrm{~km} / \mathrm{s}$ (magenta bars) for group 2 events or the independently constrained $V_{r}$ for group 1 events (stars), plotted versus $M_{w}$. Tsunami earthquakes are highlighted with red stars. Outlier events are labeled. The linear and log averages of the entire population are indicated by the labeled green dashed lines with units of $\mathrm{N} \mathrm{m} / \mathrm{s}^{3}$. Note the very tight range of values for each event. The tsunami earthquakes appear to have a distinct baseline value of $\sim 3.0 \times 10^{15} \mathrm{~N} \mathrm{~m} / \mathrm{s}^{3}$. 
(a)

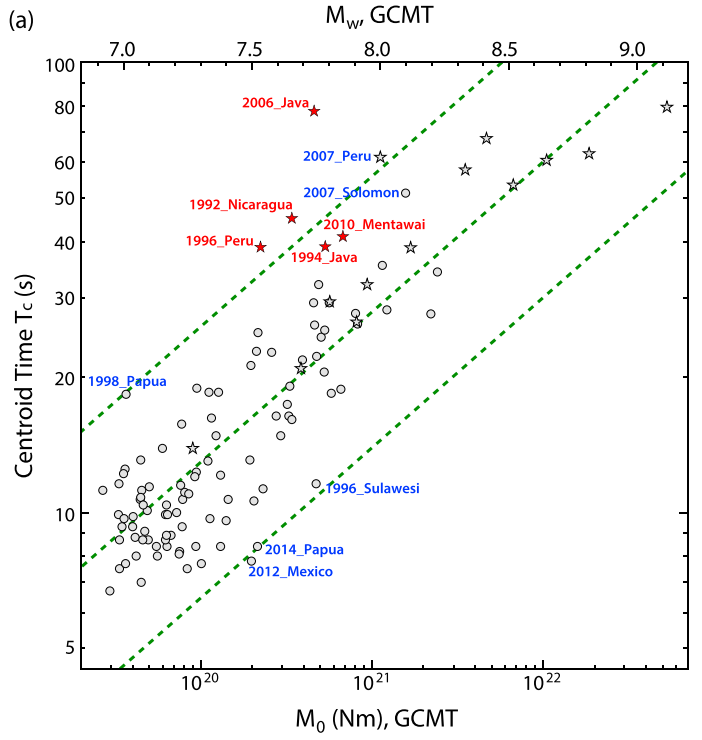

(b)

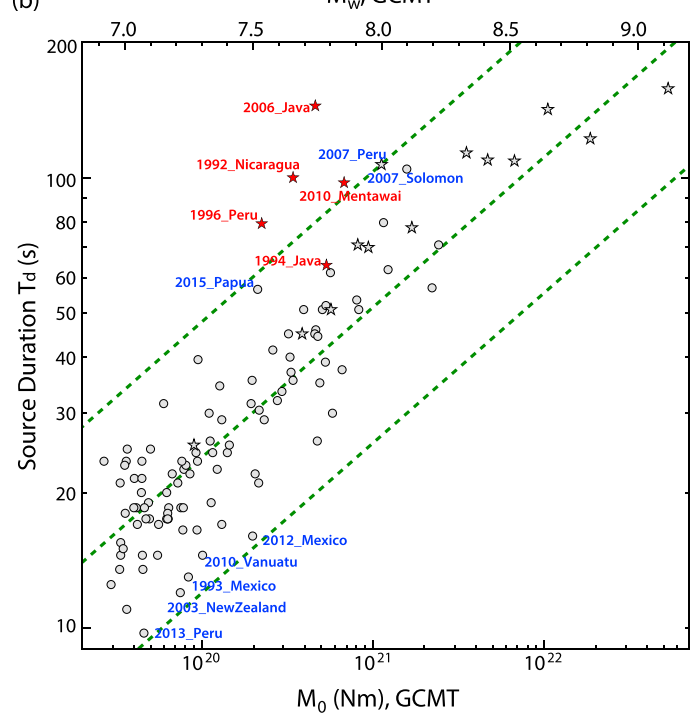

Figure 5. Comparison of finite-fault model estimates of (a) source time function centroid time shift, $T_{c}$, and (b) total source time function duration, $T_{d}$, with seismic moment (lower scale) and $M_{w}$ (upper scale). The circles indicate solutions found assuming $V_{r}=2.5 \mathrm{~km} / \mathrm{s}$. The stars use independently constrained $V_{r}$ from detailed studies. Tsunami earthquakes are highlighted in red, and outlying events are identified. The green dashed lines correspond to slopes of 1/3 with intercepts varying by factors of 2 .

low stress drop and low rupture speed, but $V_{r}^{3} \Delta \sigma_{E}$ or the rupture speed-scaled stress drop, $\left(\frac{V_{r}}{V_{r 0}}\right)^{3} \Delta \sigma_{E}$, $\left(V_{r 0}\right.$ is a reference rupture speed, e.g., $\left.2.5 \mathrm{~km} / \mathrm{s}\right)$ is another good diagnostic parameter for tsunami earthquakes.

\section{Scaling Relationships}

Given the intrinsic limitations of source parameters estimated from teleseismic analyses, we will explore the scaling relationships for (1) relatively robustly measured source parameters, including source total duration and centroid time, moment-scaled radiated energy, and apparent stress; (2) less well resolved source parameters such as stress drop and rupture area estimated from slip models with variable rupture expansion velocities; and (3) dynamic earthquake source parameters such as radiation efficiency and fracture energy, which have high uncertainty due to combined errors in both radiated energy and stress drop estimates.

\subsection{Robust Scaling Relationships}

\subsubsection{Source Duration and Centroid Time}

We can approximately relate the source duration $\tau$ for a simple rupture to other seismic parameters following Kanamori and Anderson [1975] by

$$
\tau \propto \frac{L}{V_{r}} \propto \frac{\left(M_{0} / \Delta \sigma\right)^{1 / 3}}{V_{r}},
$$

where $L$ is the fault length, $V_{r}$ is the rupture expansion velocity, $M_{0}$ is the seismic moment, and $\Delta \sigma$ is the stress drop. Here the fault width, $W$, and final slip, $D$, are assumed to scale with $L$. The centroid time $T_{c}$ has a similar basic scaling relation. If we assume uniform slip on a rectangular rupture area as a generic example, we can more explicitly write the centroid time $T_{c}$ as

$$
T_{c}=\left(\frac{C \alpha^{2}}{\gamma^{3}}\right)^{1 / 3}\left(\frac{1}{V_{r} \Delta \sigma^{1 / 3}}\right) M_{0}^{1 / 3},
$$

where $\alpha=L / W$ is the fault aspect ratio, $C$ is a rupture shape factor for stress drop calculation, and $\gamma=L /\left(V_{r} T_{c}\right)$. $\gamma$ is 2 or 4 depending on whether the rupture is unilateral or bilateral, respectively. The term in the first parentheses is a geometrical factor, and the term in the second parentheses includes the source physical parameters $\Delta \sigma$ and $V_{r}$. We will not impose this precise model on our earthquakes, as none of them involve uniform slip on a rectangular rupture area, but the basic grouping of terms in equation (2a) holds in general for all finite ruptures. 

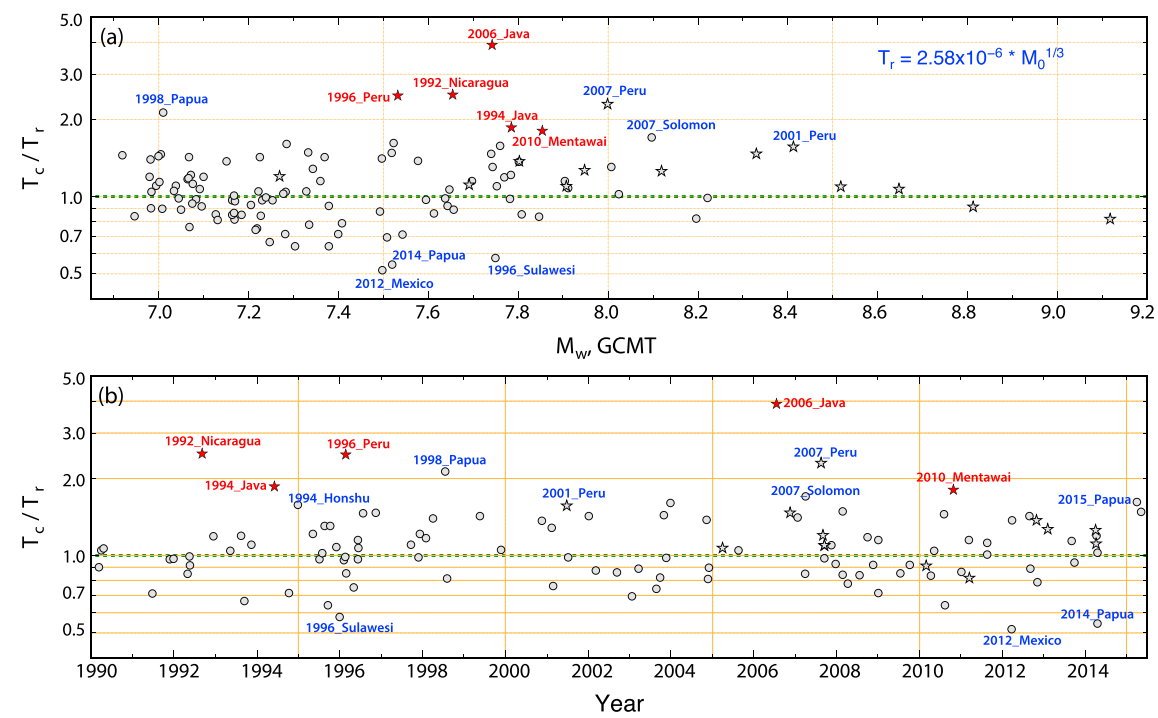

Figure 6. Source time function centroid times, $T_{c}$, from finite-fault inversions assuming $V_{r}=2.5 \mathrm{~km} / \mathrm{s}$ (circles) or independent determinations of $V_{r}$ (stars) normalized by the duration $\left(T_{r}\right)$ estimated by regression of $T_{c}$ and $M_{0}^{1 / 3}\left(M_{0}\right.$ has the unit of $\mathrm{N} \mathrm{m}$ ) with zero intercept, plotted as functions of (a) $M_{w}$ and (b) occurrence time. Events with anomalously large or small ratios are labeled. The long-duration events tend to be tsunami earthquakes (red stars), or have long intervals of weak initial slip (e.g., 2001 Peru), or are doublet ruptures e.g., (2007 Peru and 2007 Solomon Islands earthquakes).

Figure 5 a shows that centroid time $T_{c}$ estimated from the finite-fault inversions generally scales with $M_{0}{ }^{1 / 3}$ with a few significant outliers such as the 17 July $2006 M_{w} 7.8$ Java, 21 February $1996 M_{w} 7.5$ Peru, and 2 September $1992 M_{w} 7.6$ Nicaragua tsunami earthquakes, and the 15 August $2007 M_{w} 8.0$ Peru earthquake. The 2007 Peru event was characterized as a compound earthquake by Lay et al. [2010] with a $\sim 60 \mathrm{~s}$ hiatus in the seismic radiation between doublet subevents and is misleading if interpreted as a simple continuous rupture. Tsunami earthquakes all have large aspect ratios relative to deeper megathrust ruptures, and as shown in Figure 4, tsunami earthquakes have a distinct value of $V_{r}^{3} \Delta \sigma$ from the other earthquakes (here we ignore the difference between $\Delta \sigma$ and $\Delta \sigma_{E}$ ). Thus, the term given by the second parentheses should be different, which explains the deviations of tsunami earthquakes from the general trend.

We determine the relation between centroid time, $T_{c}$ and seismic moment, $M_{0}$, by linear regression for all the events excluding the significant outliers. We obtain the relationship

$$
T_{c}=2.58 \times 10^{-6} \times M_{0}^{1 / 3}
$$

where $M_{0}$ is in units of $\mathrm{N} \mathrm{m}$ and $T_{c}$ is in second. The coefficient $2.58 \times 10^{-6}$ is close to the value, $2.59 \times 10^{-6}$ $\left(1.2 \times 10^{-8}\right.$ with $M_{0}$ in dyn cm) validated in Duputel et al. [2013] using the centroid time determined by long period $W$ phase inversion. Duputel et al. [2013] applied a regression analysis to all events without excluding the outliers such as tsunami earthquakes, but the outliers are few and the relation is not very different. If we include all the earthquakes in the regression analysis, we obtain $T_{c}=2.76 \times 10^{-6} \times M_{0}^{1 / 3}$. With this scaling relationship (equation (2b)), we can predict the centroid time $\left(T_{r}\right)$ for a given seismic moment, to within a factor of 2, except for tsunami earthquakes, over the magnitude range $M_{w}=6.9-9.0$. The ratios between the measured and predicted centroid time are shown as a function of earthquake magnitude (Figure 6a) and earthquake occurrence time (Figure 6b). As emphasized by Duputel et al. [2013] the scaling relationship equation (2b) provides one of the more robust seismological scaling behaviors for major megathrust earthquakes. The outliers in these plots also provide a useful means of identifying unusual earthquakes such as tsunami earthquakes.

If we perform the regression allowing for a nonzero intercept, there is a $\sim 2 \mathrm{~s}$ offset as seismic moment approaches zero (Figure S1), which has been observed previously for the GCMT catalog [Dziewonski and Woodhouse, 1983] and the $W$ phase catalog [Duputel et al., 2013]. This may be an artifact caused by limitations of the moment rate function parameterizations in the various methods along with uncertainties in the absolute origin times used as references for the centroid time estimation. We used subfault source time functions with 


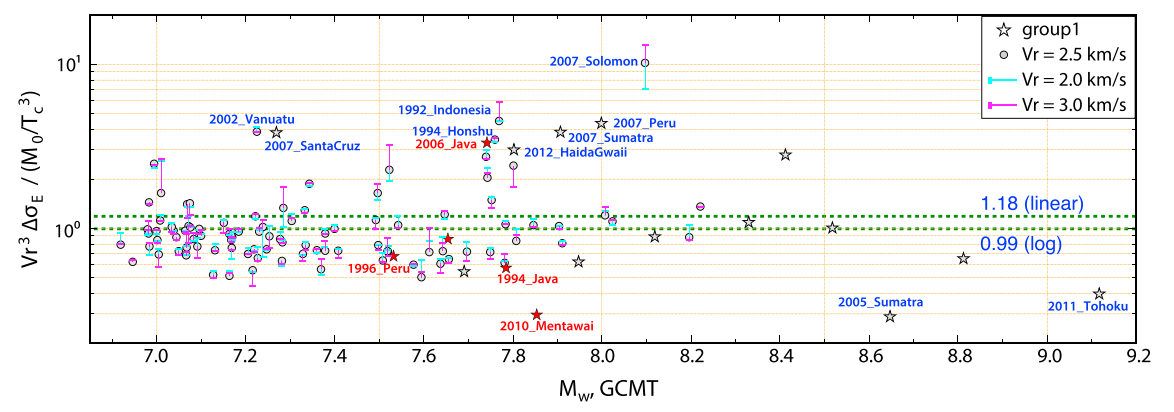

Figure 7. The ratio of $V_{r}^{3} \Delta \sigma_{E}$ (Figure 4) and $M_{0} / T_{c}^{3}$ (Figure 11) plotted as a function of $M_{w}$. This ratio isolates the geometrical factors that differ between events. The nondimensional linear and log averages are indicated by labeled dashed green lines. Tsunami earthquakes are highlighted with red stars, and outliers are labeled in both panels.

multiple triangles with $0.5 \mathrm{~s}$ half duration and $0.5 \mathrm{~s}$ sample rate for the data in our finite-fault inversions and aligned our $P$ waves by eye with subjective uncertainty. We tested whether there is any bias in the scaling by including the intercept shift, but the overall pattern of scaled centroid time does not show significant difference (Figure S2).

We apply a similar analysis to the total duration, $T_{d}$, and the result is shown in Figure $5 \mathrm{~b}$. Measurement of total duration is challenging due to variations in the moment rate functions cause by inaccurate Green's functions and inadequate modeling of water reverberations. We pick the duration windows based on our assessment of the stable source signal from multiple models for each event. The weak positive trend relative to cube root scaling is likely due to the bias discussed above concerning the total duration estimates from the moment rate functions determined using the finite-fault inversion with positivity constraints. Comparisons of $T_{d}$ with earlier studies for smaller events are considered in the companion paper (Paper 2).

\subsubsection{Geometrical Factor}

To isolate the geometrical factor, we rewrite equation (2a) as

$$
\frac{C \alpha^{2}}{\gamma^{3}}=\left(V_{r}^{3} \Delta \sigma\right) /\left(M_{0} / T_{c}^{3}\right),
$$

which means that the ratio of the well-constrained $V_{r}^{3} \Delta \sigma$ determined by slip inversion to $M_{0} / T_{c}^{3}$ (Figure S3 shows this term as a function of $M_{w}$ ) determined by the $M_{0}$ versus $T_{c}^{3}$ relation gives the geometrical factor. For purposes of illustration, we consider a reference fault geometry with a unilateral $(\gamma=2)$ thrust fault and an aspect ratio $\alpha=3$. For this geometry the geometrical factor, $C \alpha^{2} / \gamma^{3}$, is close to 1. Figure 7 shows the ratio, $\left(V_{r}^{3} \Delta \sigma_{E}\right) /\left(M_{0} / T_{c}^{3}\right)$, as a function of $M_{w}$. For most events, the ratio is close to 1 . Small $C \alpha^{2} / \gamma^{3}$ can be due to strong bilateral rupture, such as for the 11 March $2011 M_{w} 9.0$ Tohoku earthquake. Large values can result from large aspect ratio ruptures like the 17 July $2006 M_{w} 7.8$ Java and 1 April $2007 M_{w} 8.1$ Solomon Islands earthquakes or unusually long duration doublet earthquakes like the 15 August $2007 M_{w} 8.0$ Peru earthquake. Although the cause of some of the outliers in Figure 7 is not obvious, the overall trend is what is expected. Note that we do not actually estimate specific values of $\alpha, C$, or $\gamma$, but use the stability of the terms on the right side of equation (2c) to give the overall combined geometrical factor behavior.

Source scaling analyses often explicitly assume that the geometrical factors are constant for all earthquakes by assuming, for example, a circular rupture model for computing stress drop. For such an assumption we can predict a stress drop $\left(\Delta \sigma_{T, G}\right)$ using the measured seismic moments and centroid source durations along with a specified rupture speed and equation (2b). If $C=1, \alpha=3$, and $\gamma=2$ for unilateral rupture, $C \alpha^{2} / \gamma^{3}$ is about 1.125 which is close to the average value from the ratios of $M_{0} / T_{c}^{3}$ and $V_{r}^{3} \Delta \sigma_{E}$ in Figure 7. Assuming a constant $V_{r}=2.5 \mathrm{~km} / \mathrm{s}$ for all events, we obtain estimates of $\Delta \sigma_{T, G}$ that are compared with our measured energy-related stress drops $\Delta \sigma_{E}$ using the same $V_{r}$ for group 2 events in Figure $\mathrm{S} 4 \mathrm{a}$. For most earthquakes, there is reasonable similarity of the two stress drop estimates, but there can be significant errors in the estimate for some events if the real geometric factor is not determined by finite-fault inversion as in Figure 7.

\subsubsection{Moment-Scaled Radiated Energy and Apparent Stress}

We estimate the radiated energy $E_{R}$ for each station from the observed ground velocity spectra following the method of Venkataraman and Kanamori [2004], and then average the station estimates in a logarithmic sense 

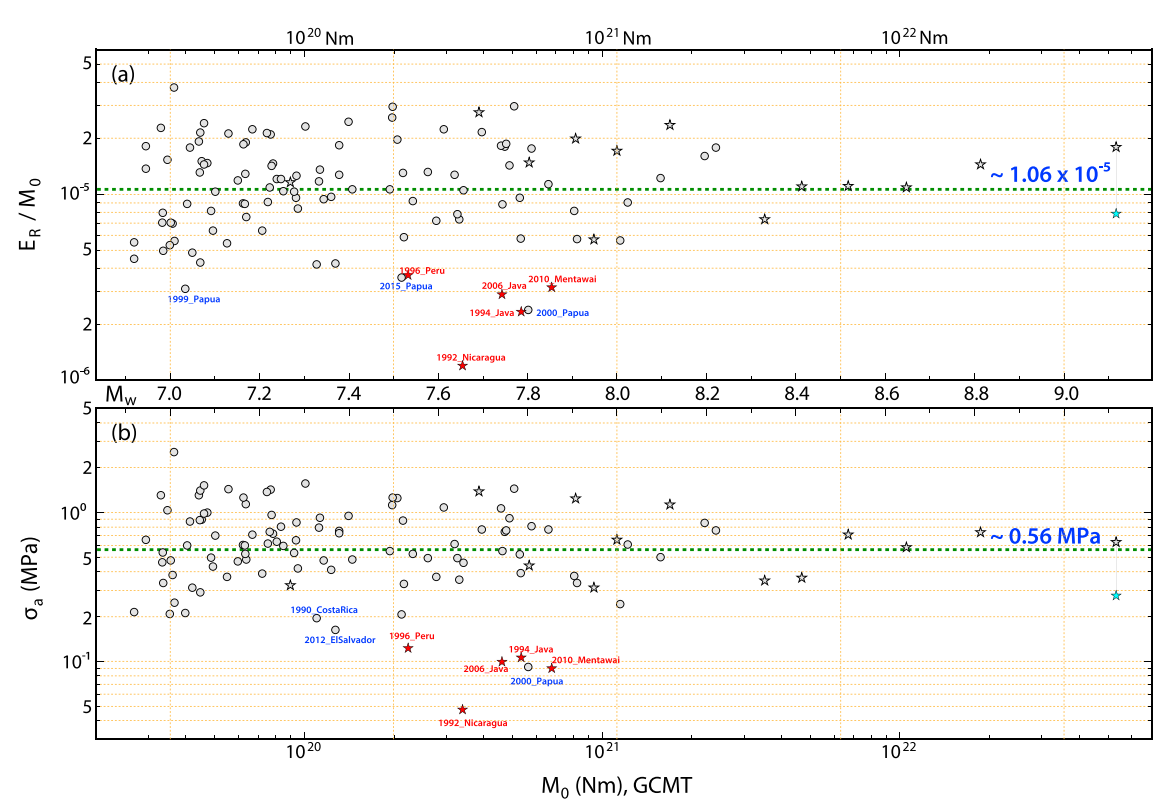

Figure 8. (a) Moment-scaled radiated energy estimates and (b) apparent stress versus GCMT seismic moment and $M_{w}$. Circles indicate determinations that estimate low frequency energy contributions from finite fault models with $V_{r}=2.5 \mathrm{~km} / \mathrm{s}$ and stars indicate finite fault models with independently estimated $V_{r}$. The low frequency energy estimates are very weakly dependent on $V_{r}$, so the plot is very similar to those for different choices of $V_{r}$. Tsunami events are highlighted with red stars. Outliers are labeled. The average values over the entire range are given by the labeled dashed green lines. The cyan star indicates the moment-scaled radiated energy and apparent stress calculated with the radiated energy for the 2011 Tohoku-oki event from Lay et al. [2012].

(i.e., geometric average) to estimate the radiated energy for frequencies above $0.05 \mathrm{~Hz}$. The time window for each signal is carefully chosen to include most of $P$ wave group energy arrivals, while minimizing the effect of scattered coda energy and $P P$ phases. A broadband source spectrum is obtained for each event by combining the spectrum of the moment rate functions estimated with finite-fault inversions for frequencies below $0.05 \mathrm{~Hz}$ and the average displacement spectrum estimated from attenuation-corrected $P$ waves for frequencies in the range $0.05-1.0 \mathrm{~Hz}$. The broadband spectrum thus obtained is used to estimate the total radiated energy by adding in the low frequency contribution. In some cases there is a substantial contribution from frequencies less than $0.05 \mathrm{~Hz}$, especially for tsunami earthquakes [Ye et al., 2013b; Lay et al., 2013a]. Our method for estimating radiated energy and all other routine methods in use do not fully account for the interaction between the source and the free surface. The interaction is particularly important for shallow, shallowly dipping large events like the 2011 Tohoku-oki earthquake. Rivera and Kanamori [2014] use a normal mode approach to correctly make the volumetric strain energy calculation, and they obtain a lower value for the 2011 Tohoku-oki event than we obtain. Only a few events are likely to be significantly affected, but future revision of radiated energy calculations with this more comprehensive approach can be anticipated.

The total radiated energy $E_{R}$ scaled by seismic moment is an important characterization of earthquake dynamics. There are numerous observations and debates about the influence of earthquake size on $E_{R} / M_{0}$ [e.g., Venkataraman and Kanamori, 2004; Walter et al., 2006]. Figure 8a shows our measurements of this ratio using the radiated energy estimates up to $1 \mathrm{~Hz}$ as a function of $M_{w}$ and $M_{0}$. The tsunami earthquakes clearly stand out from the other large megathrust events in this study (Figure 8a), along with a few other earthquakes with strong observed tsunami or very shallow ruptures, such as the 17 November 2000 (21:01 GMT) Papua [Geist and Parsons, 2005], 27 August 2012 El Salvador [Ye et al., 2013b], 6 February 2013 Santa Cruz Islands [Lay et al., 2013a], and 5 May 2015 Papua earthquakes. The low $E_{R} / M_{0}$ of tsunami events relative to comparably large earthquakes is compatible with the results of Newman and Okal [1998] despite our values being systematically larger. Moment-scaled radiated energy measures have large scatter from $1 \times 10^{-6}$ to $4 \times 10^{-5}$, but no obvious magnitude dependence. The average value of $E_{R} / M_{0}$ for the 114 events in this study is $1.06 \times 10^{-5}$, or $\theta=\log _{10}\left(E_{R} / M_{0}\right)=-4.97$, which is quite consistent with the value $\theta=-4.74$ from Convers and Newman [2011] for all $M_{w}>6.7$ thrust events from 1997 to mid-2010 and with the 
compilation of all measurements for events from $M_{w} 1.5-9.2$ by Baltay et al. [2014], for which our data fill in a large gap in the $M_{w} 7.0-8.5$ range.

A related source parameter that is often considered is apparent stress, defined as the product of rigidity and moment-scaled radiated energy,

$$
\sigma_{a}=\mu \frac{E_{R}}{M_{0}}=\frac{E_{R}}{A \cdot D}
$$

where $D$ is average slip, $A$ is source rupture area, and $\mu$ is rigidity. The apparent stress was used by Wyss [1970] to study the difference in the state of stress between shallow and deep earthquakes. The recent advances in broadband seismology have enabled us to estimate $E_{R}$ accurately, making this parameter more meaningful. The total strain (potential) energy release in an earthquake is given by $\Delta W=\bar{\sigma} D A=\left(\frac{\bar{\sigma}}{\mu}\right) M_{0}$, where $\bar{\sigma}$ is the average stress on the fault plane [Kostrov, 1973; Dahlen, 1977]. Then the radiated energy $E_{R}$ can be written as $E_{R}=\eta \bar{\sigma} D A=\sigma_{a} D A$ where $\eta$ is the seismic efficiency, and $\sigma_{a}=\eta \bar{\sigma}$ is the apparent stress. Thus, $\sigma_{a}$ is a part of the average stress that is responsible for seismic energy radiation and is the stress that represents the dynamic characteristics of an earthquake. The remainder of the average stress is used as work done on the fault plane.

From equation (3), we can think of apparent stress as radiated energy per unit rupture area, per unit slip, although the energy is not necessarily radiated from the fault plane and the volumetric strain energy release must be considered [Rivera and Kanamori, 2005]. It has been used for interpreting fracture energy and slipweakening models [e.g., Abercrombie and Rice, 2005; Rice, 2006]. If the rigidity, $\mu$, is assumed to be constant for all earthquakes in various environments, say $30 \mathrm{GPa}$, as used in many previous studies, the apparent stress is directly proportional to the moment-scaled radiated energy that we show in Figure 8a. Given that we have variable rigidity in our source models, we compute apparent stress parameters using the slip-weighted average rigidity for each rupture model. Resulting variations of apparent stress with seismic moment for our large events (Figure $8 \mathrm{~b}$ ) are naturally quite similar to those of $E_{R} / M_{0}$, but the shallow tsunami/tsunamigenic earthquakes are more separated from the general trend, due to the product of low $E_{R} / M_{0}$ and low source region rigidity. The average apparent stress for the entire population of events is about $0.56 \mathrm{MPa}$. Because the actual values of rigidity, particularly at very shallow depth in the megathrust environment are not well constrained, it is difficult to formally estimate uncertainties in the apparent stress values. However, apart from the baseline shift to low values around $0.1 \mathrm{MPa}$ for tsunami earthquakes, there is no clear dependence on earthquake size for our population of major and great megathrust events.

\subsection{Stress Drop}

Stress drop is an important measure of the change of static stress on a fault before and after an earthquake. Despite this importance, the static stress drop cannot be defined precisely, and some ambiguity remains. The stress drop is a function of spatial derivatives of slip, but detailed slip distribution is usually difficult to determine in practice. Given this difficulty, it is typically estimated from the ratio of the average coseismic slip to a characteristic fault dimension and is therefore subject to large uncertainty due to the low resolution of estimates of both of those parameters. In reality, the stress drop varies spatially over the rupture area, as expected from the heterogeneous slip distributions of kinematic finite-fault models; it evolves at each point during nucleation, rupture, and healing processes, as demonstrated in dynamic rupture simulations. Because of this complexity, estimations of stress drops by different investigators vary even for similar slip distributions depending on how averaging is done. To stabilize the stress drop estimation procedure we use the following two methods for all events: (1) averaging the stress drop distribution for finite-fault models weighted by the spatially varying slip distribution and (2) using the rupture area of the well-resolved slip regions and the average slip over it.

\subsubsection{Energy-Related Stress Drop}

Based on consideration of energy partitioning, the energy-related stress drop $\left(\Delta \sigma_{E}\right)$ has been proposed as the spatial average of the stress drop weighted by slip [Noda et al., 2013; Ye et al., 2013c],

$$
\Delta \sigma_{E}=\frac{\int_{\Sigma} \Delta \sigma_{1} \Delta u_{1} \mathrm{~d} S}{\int_{\Sigma} \Delta u_{1} \mathrm{~d} S},
$$

where $\Delta \sigma_{1}$ and $\Delta u_{1}$ are components of stress drop and slip at each subfault in the overall slip distribution, as shown in the Figure 2 and Texts S1 and S2 for all earthquakes. 

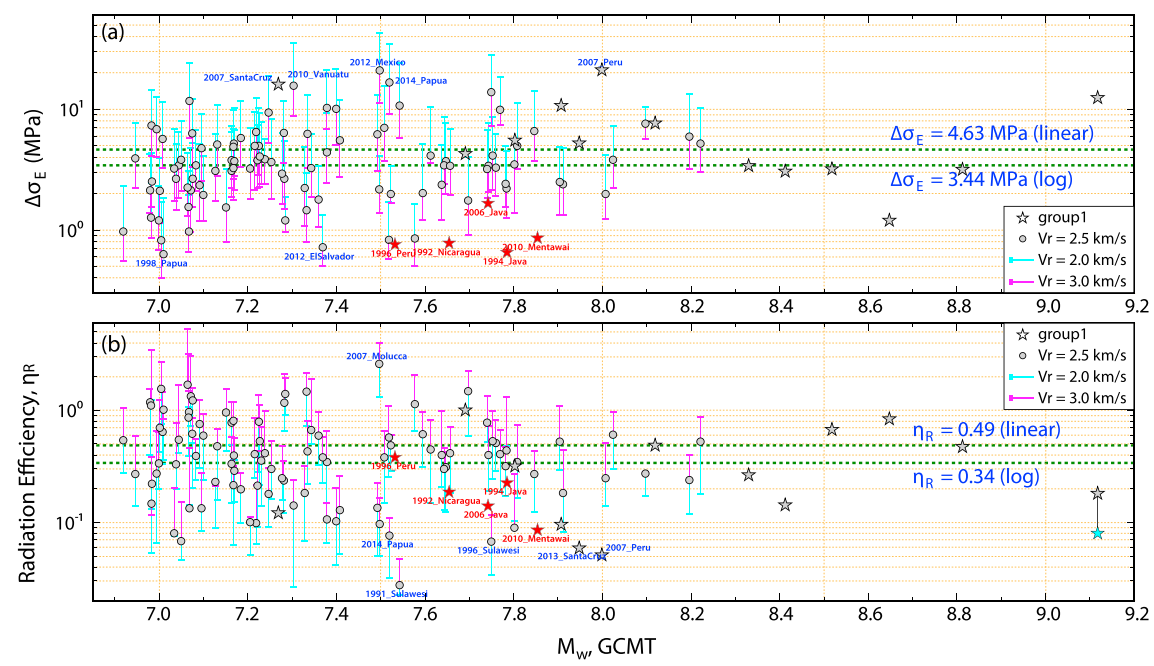

Figure 9. (a) The range of stress drop, $\Delta \sigma_{E}$, from variable slip finite source models with $V_{r}=2.0 \mathrm{~km} / \mathrm{s}$ (upper cyan estimates), to $V_{r}=2.5 \mathrm{~km} / \mathrm{s}$ (circles), to $V_{r}=3.0 \mathrm{~km} / \mathrm{s}$ (lower magenta estimates), plotted versus $M_{w}$. The stars are for group 1 finite fault models with independent estimates of $V_{r}$. (b) Corresponding values of radiation efficiency for models with different $V_{r}$ versus magnitude. Linear and logarithmic averages of $\Delta \sigma_{E}$ and $\eta_{R}$ are indicated by labeled horizontal green lines. Events with high or low values are labeled. Tsunami earthquakes are highlighted with red stars. The cyan star indicates radiation efficiency calculated with the radiated energy for the 2011 Tohoku event from Lay et al. [2012].

As mentioned earlier, strong trade-off exists between the stress drop and $V_{r}$. Given this trade off, we compute $\Delta \sigma_{E}$ for three slip models with $V_{r}=2 \mathrm{~km} / \mathrm{s}, 2.5 \mathrm{~km} / \mathrm{s}$, and $3 \mathrm{~km} / \mathrm{s}$ and use the case with $V_{r}=2.5 \mathrm{~km} / \mathrm{s}$ as a reference model. However, the rupture speed for the individual event may differ from $2.5 \mathrm{~km} / \mathrm{s}$, and variation of $V_{r}$ over a range of at least 2 to $3 \mathrm{~km} / \mathrm{s}$ is possible.

Figure 9a shows $\Delta \sigma_{E}$ thus calculated as a function of $M_{w}$. No systematic variation in $\Delta \sigma_{E}$ with $M_{w}$ is seen. The average $\Delta \sigma_{E}$ is $\sim 3.4-4.6 \mathrm{MPa}$ for the $114 M_{w} \geq 7$ events we analyzed with the assumed $V_{r}$ of $2.5 \mathrm{~km} / \mathrm{s}$ for group 2 events. There is a factor of $\sim 2$ variation of $\Delta \sigma_{E}$ for rupture velocities varying from $2.0 \mathrm{~km} / \mathrm{s}$ to $2.5 \mathrm{~km} / \mathrm{s}$ or from $2.5 \mathrm{~km} / \mathrm{s}$ to $3.0 \mathrm{~km} / \mathrm{s}$. The values of $\Delta \sigma_{E}$ with different $V_{r}$ for all the earthquakes ranges from $\sim 0.4 \mathrm{MPa}$ to $\sim 40 \mathrm{MPa}$, with $\Delta \sigma_{E}$ less than $2 \mathrm{MPa}$ for tsunami earthquakes. Only a few events have $\Delta \sigma_{E}$ larger than $10 \mathrm{MPa}$. While there is no overall magnitude dependence, there is a tendency for scatter to decrease from a factor of $\sim 100$ for $M_{w} 7.0-7.9$ events to a factor of $\sim 10$ for $M_{w}>8$ (Figure 9a). Random resampling of stress drop values in the two magnitude bands indicates that the relatively small scatter for large events is not an artifact of the smaller number of observations (Figure S6). For earthquakes smaller than 7, stress drops are most frequently estimated from the spectral corner frequencies, and the estimates of stress drop show 3 to 4 orders of magnitude variation [e.g., Shearer et al., 2006; Allmann and Shearer, 2009]. The large scatter in stress drop estimates reflects uncertainty in source modeling but also represents actual variations of stress heterogeneity in the crust. The heterogeneous state of stress in the crust is indicated by the variations in observed body wave frequency content, waveform complexity, and ground shaking duration (see the individual rupture models and data fits in Texts S1 and S2 Figures). The reduced scatter in stress drop as event size increases may be a result of more extensive averaging over stress heterogeneity on the fault plane intrinsic for larger ruptures.

The stability of individual event values of $V_{r}^{3} \Delta \sigma_{E}$ for a range of finite-fault models allows us to estimate the rupture velocities for a range of assumed stress drops. Figure 10a shows the rupture velocities consistent with stress drops varying from $2 \mathrm{MPa}$ to $7 \mathrm{MPa}$ for each event, as a function of seismic moment. The inferred rupture velocities range from $\sim 1 \mathrm{~km} / \mathrm{s}$ (for tsunami earthquakes) to $\sim 4 \mathrm{~km} / \mathrm{s}$, with an average of $2.26 \mathrm{~km} / \mathrm{s}$.

\subsubsection{Effective Rupture Area}

The most common seismological estimates of average static stress drop $\left(\Delta \sigma_{s}\right)$ for large earthquakes are based on the seismic moment and fault dimensions with assumed fault geometry. For large subduction zone 

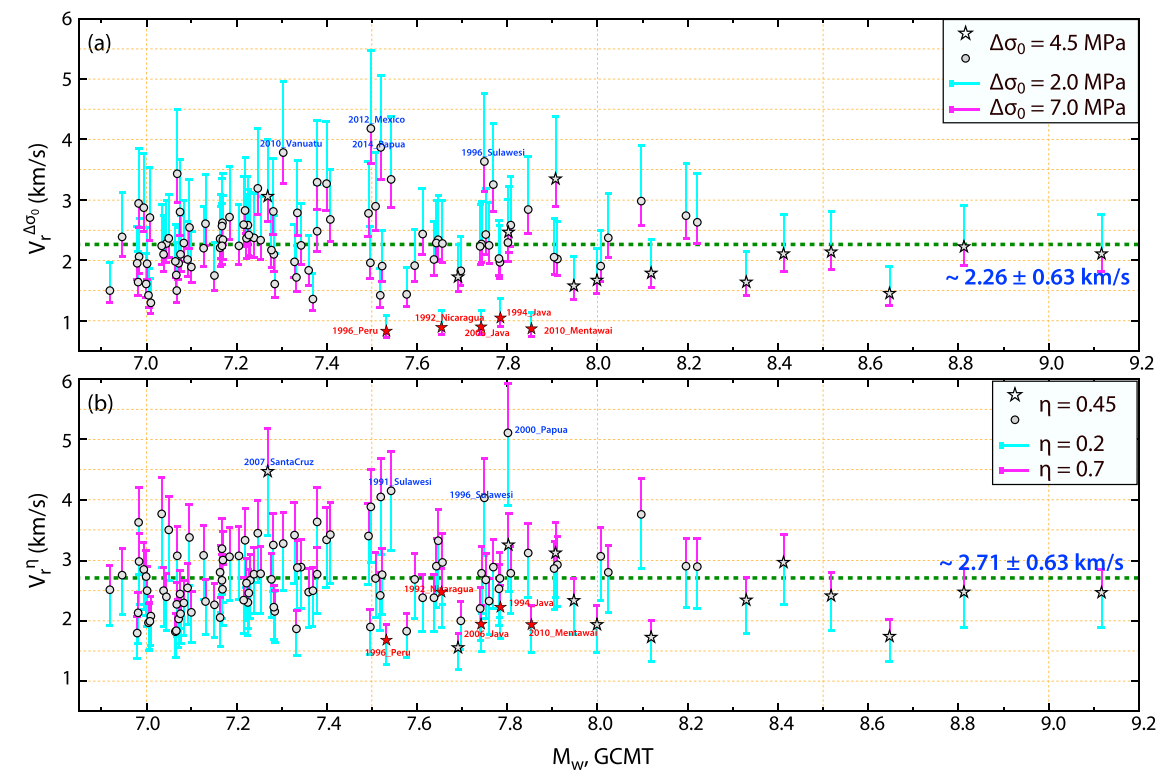

Figure 10. (a) Calculations of rupture expansion velocity $V_{r}$ for each event consistent with constant stress drop $\Delta \sigma_{0}$ of 2.0 $\mathrm{MPa}$ (cyan bars), 4.5 MPa (circles and stars), and $7 \mathrm{MPa}$ (magenta bars) plotted versus $M_{w}$. The individual event values of $V_{r}^{3} \Delta \sigma$ from finite-fault models (Figure $4, V_{r} 2.5 \mathrm{~km} / \mathrm{s}$ for group 2 events) are used to estimate $V_{r}$. (b) Calculations of rupture velocity for each event consistent with the stress drops derived with constant radiation efficiency of 0.2 (cyan bars), 0.45 (circles and stars), and 0.7 (magenta bars) (see example in Figure S4b) plotted versus $M_{w}$. The individual event values of $V_{r}^{3} \Delta \sigma$ from finite fault models (Figure 4) are also used to estimate $V_{r}$. Tsunami earthquakes are highlighted with red stars and outliers in the $V_{r}$ estimates are identified. The average $V_{r}$ for each population is indicated by the labeled dashed green line in each panel.

interplate earthquakes, stress drop is often calculated using the average slip from finite-fault models using the relation [Kanamori and Anderson, 1975],

$$
\Delta \sigma_{s}=\frac{7 \pi}{16} \mu \frac{D}{a}=\frac{7 \pi^{3 / 2}}{16} \frac{M_{0}}{A^{3 / 2}}
$$

where $D$ is the average slip, $a$ is a radius of circular fault area equal to the estimated source rupture area $A$, and $\mu$ is rigidity. The relation equation (5) is for a circular crack, but it is used approximately for any fault with area A. The seismic moment $M_{0}$ can be taken from the well-determined long-period measurements; we use GCMT estimates in this study. The critical issue is the estimation of the rupture dimension or rupture area, which is difficult to determine from teleseismic body wave data, as mentioned above. In our finite-fault inversions, we initially use a large enough fault plane to accommodate the slip zone well within it, adjusting the model dimensions based on the source complexity and any independent information about the rupture velocity. After settling on a final grid and rupture velocity, we apply a trimming threshold $\xi$, to our final inverted slip distribution. This removes subfaults with a seismic moment smaller than $\xi$ times the moment of the subfault with the largest moment. The choice of $\xi$ has a direct effect on the estimates of effective rupture area $\left(A_{\text {eff }}\right)$ and the associated equivalent circular fault radius, $a$, and to a lesser extent on the estimated value of $D$. Typical values of $\xi$ used in our own previous work have been 0.1 to 0.2 . $\xi$ is not theoretically constrained and can vary from event to event depending on the nature of the slip distribution, the data coverage, and the fault model parameterization.

Instead of computing $\Delta \sigma_{s}$ with an arbitrarily chosen $\xi$, we varied $\xi$ to find $\Delta \sigma_{s}$ that matches the energy-related stress drop $\Delta \sigma_{E}$ for the same event. Figure 11a shows that the resulting trimming threshold ranges from $\sim 0.08$ to 0.4 with an average of $\sim 0.17$. This is compatible with the results of numerical calculations of strain energy for many heterogeneous stress drop distributions [Noda et al., 2013]. Overall, a use of $\xi \sim 0.17$ is sufficient to remove most of the poorly resolved model components and to provide a reasonable source area for the stress drop determination. The energy-related $\Delta \sigma_{E}$ presented in this study can be compared directly with the static stress drop estimated with $\xi \sim 0.15$ in our previous studies [e.g., Ye et al., 2013a; Lay et al., 2013a, 2013b]. Texts S1 and S2 Figures give corresponding stress drop estimates for $\xi=0.15$. The values of $\xi$ do not depend much on the assumed rupture expansion velocity as shown in the Figure 11a. 

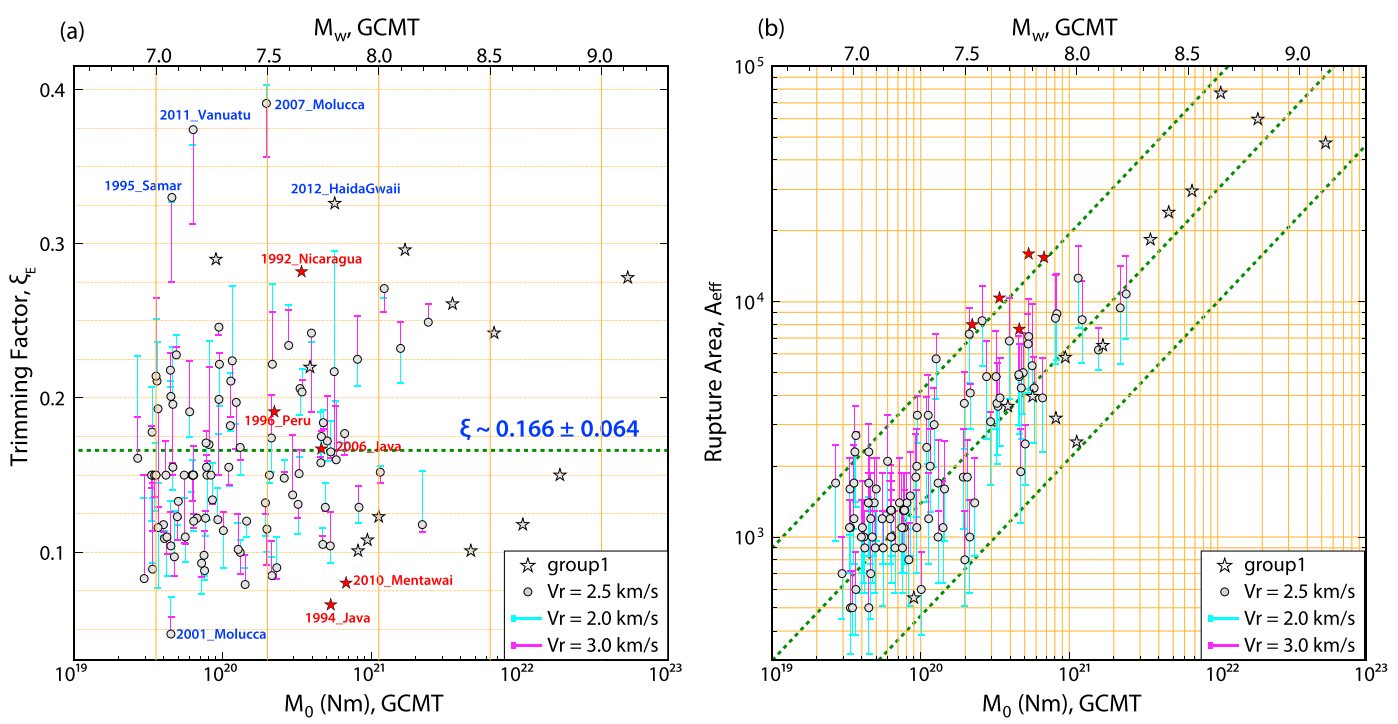

Figure 11. (a) Determinations of finite fault model trimming factors $\xi_{E}$ that provide circular rupture models with uniform average slip that give stress drops that match $\Delta \sigma_{E}$ calculations and (b) the corresponding trimmed rupture area $\left(A_{\text {eff }}\right)$ for each model, plotted versus seismic moment (lower axis) and $M_{w}$ (upper axis). Circles are trimming factors for finite source models that assume $V_{r}=2.5 \mathrm{~km} / \mathrm{s}$, cyan bars indicate the trimming for models with $V_{r}=2.0 \mathrm{~km} / \mathrm{s}$ that match the corresponding model estimates of $\Delta \sigma_{E}$, magenta bars indicate the trimming for models with $V_{r}=3.0 \mathrm{~km} / \mathrm{s}$ that match the corresponding model estimates of $\Delta \sigma_{E}$, and stars are for finite source models with independently constrained $V_{r}$. The average trimming factor is about 0.17 (horizontal green line in Figure 11a).

The scaling between rupture area and seismic moment for major megathrust events is important for many applications, including tsunami early warning and long-term earthquake hazard estimation. For the specific $\xi$ values that give $\Delta \sigma_{s}=\Delta \sigma_{E}$, we have corresponding effective rupture areas ( $A_{\text {eff }}$ ) with significant slip from the finite-fault models. Figure $11 \mathrm{~b}$ shows that $A_{\text {eff }}$ generally scales with $M_{0}^{2 / 3}$ with small scatter, ranging over 1 order of mag-

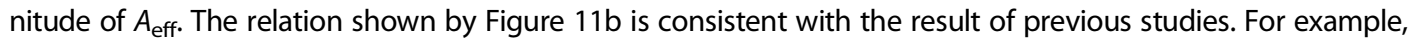
Figure 2 of Kanamori and Anderson [1975] indicates a relation $\log M_{0}=1.5 \log A+15.05\left(M_{0}\right.$ in N m, $A$ in $\left.\mathrm{km}^{2}\right)$, and Figure 16 of Wells and Coppersmith [1994] indicates a relation $\log M_{0}=1.515 \log A+15.0$. The middle dotted line on Figure 11b which passes through the group 1 events and the middle of the points for group 2 events calculated with $V_{r}=2.5$ is given by $\log M_{0}=1.5 \log A+15.3$. Thus, the rupture speed $V_{r}=2.5 \mathrm{~km} / \mathrm{s} \mathrm{seems}$ to be a reasonable average rupture speed.

\subsection{Radiation Efficiency}

A parameter that is commonly used to connect kinematic observations with earthquake dynamic models is radiation efficiency, $\eta_{R}$, defined as

$$
\eta_{R}=\frac{E_{R}}{\Delta W_{0}}=\frac{2 \mu}{\Delta \sigma} \frac{E_{R}}{M_{0}}=2 \cdot \frac{\sigma_{a}}{\Delta \sigma},
$$

where $E_{R}, \Delta W_{0}, \sigma_{a r}$ and $\Delta \sigma$ are radiated energy, available potential energy, apparent stress, and static stress drop, respectively. The radiation efficiency, $\eta_{R}$, is different from the efficiency, $\eta$, which is the ratio of $E_{R}$ to the total potential energy change $\Delta W$. Thus,

$$
\eta=\frac{\Delta \sigma}{2 \bar{\sigma}} \eta_{R} \leq \eta_{R}
$$

Radiation efficiency is useful for understanding the energy partitioning between the radiated energy and the mechanically and thermally dissipated energy in the fault zone and can be related to the rupture speed. Kanamori et al. [1998] found very low radiation efficiency for the slowly rupturing main phase of the 1994 $M_{w} 8.3$ deep Bolivia earthquake, indicative of a dominant role of dissipative mechanical and thermal processes during that deep earthquake faulting. The physical requirement of $\eta_{R}<1$ (assuming no final stress undershoot) has subsequently been used to constrain the rupture dimension of the 24 May $2013 M_{w} 8.3$ deep-focus Sea of 
Okhotsk earthquake by Ye et al. [2013a]. The rupture of the Okhotsk earthquake appears to have been faster and more brittle with higher radiation efficiency than the Bolivia earthquake.

Theoretically, the radiation efficiency varies between 0 and 1 as a function of rupture speed for mode II and III type ruptures [e.g., Kanamori and Rivera, 2006]. It is physically possible that radiation efficiency as defined by equation (6) can exceed 1 if there is stress recovery that results in small final stress drop, and the available energy defined by $\Delta W_{0}=\frac{\Delta \sigma}{2 \mu} M_{0}$ in equation (6) is underestimated. We computed the radiation efficiency using our independently estimated source parameters and examine the distribution of values. We find that about $15 \%$ of the total set of events has a calculated radiation efficiency larger than 1 if we use the energy-related stress drop $\Delta \sigma_{E}$ and average rigidity from the finite-fault models (Figure $9 \mathrm{~b}$ ). About $10 \%$ of our events have very low estimates of radiation efficiency $(<0.1)$, which suggests strongly dissipative processes, likely with strong thermal heating effects. It is interesting that several events in Papua and Sulawesi regions have particularly low values (Figure 9b). The average estimates of radiation efficiency are 0.49 (linear) and 0.34 (logarithmic).

The scatter of the radiation efficiency decreases with the magnitude (Figure 9b), and a negative correlation between radiation efficiency and stress drop for our measurements (Figure S5a) results from the relative constancy of moment-scaled radiated energy. The trend is quite systematic even for events with low radiation efficiency, so this behavior indicates that stress drop variations dominate the radiation efficiency estimates. Correlations between radiation efficiency and moment-scaled radiated energy are more scattered (Figures S5b and S5c). Essentially, moment-scaled radiated energy does not increase as fast as stress drop increases, lowering the efficiency. A possible interpretation is that when higher stress is involved during fault slip more energy is dissipated by microcracking, deformation, or some thermal process.

We can use equation (6) to predict a stress drop $\left(\Delta \sigma_{\eta}\right)$ under the assumption of a specific value of radiation efficiency, together with the measured values of moment-scaled radiated energy for each earthquake. Figure S4b shows that $\Delta \sigma_{\eta}$ for $\eta=0.5$, has some correlation with measured $\Delta \sigma_{E}$, but less than that for $\Delta \sigma_{\mathrm{T}, \mathrm{G}}$. The overall population of values of $\Delta \sigma_{\eta}$ is slightly low relative to $\Delta \sigma_{E}$, which could be redressed by assuming a somewhat lower value of $\eta$. Estimates of $V_{r}$ can again be made using the stable event-specific values of $V_{r}^{3} \Delta \sigma_{E}$ replacing $\Delta \sigma_{E}$ with the stress drop values estimated from specified values of radiation efficiency $\left(\Delta \sigma_{\eta}, \eta=0.2\right.$ to 0.7$)$. Figure $10 \mathrm{~b}$ shows that this gives a range of inferred rupture velocities from $\sim 1.5 \mathrm{~km} / \mathrm{s}$ to $\sim 4 \mathrm{~km} / \mathrm{s}$ with an average $\sim 2.7 \mathrm{~km} / \mathrm{s}$. The less distinct rupture velocity estimates for tsunami earthquakes indicate that this procedure has limitations but retrieves the overall behavior fairly well. While $V_{r}$ is directly parameterized in finite-fault models rather than stress drop or radiation efficiency, the overall consistency of the $V_{r}$ values with reasonable ranges of stress drop and radiation efficiency indicates that reasonable values are used.

Figure 12a plots estimates of radiation efficiency for our very large events along with measurements from Abercrombie and Rice [2005] for smaller events as a function of average slip $D$ for each event. The $\eta_{R}$ values for major and great events are for the source models with stress drop $\Delta \sigma_{E}$ and the average rigidity across the slip distribution, while a uniform source rigidity of $30 \mathrm{GPa}$ is assumed for the smaller crustal events. There is a trend of slightly increasing radiation efficiency with increasing average slip from $1 \mathrm{~mm}$ up to $1 \mathrm{~m}$, but then radiation efficiency appears to decrease for yet larger slip up to $20 \mathrm{~m}$. The pattern involves data from different faulting geometries and source environments for the small and major events, so it is possible that different mechanisms affect $\eta_{R}$ across the combined population. If we consider just the major and great events, radiation efficiency tends to decrease with slip. Diverse mechanisms may operate for the largest slip events that distinguish them from lower slip events.

While our results for radiation efficiency are obtained from an extensive data set of very large megathrust events, further constraints on source parameters using regional data with better spatial resolution of rupture dimensions are likely needed before drawing more definitive conclusions from these measurements.

\subsubsection{Fracture Energy}

Fracture energy per unit area, $G$, which involves all resistance to rupture expansion at the rupture tip including plastic yielding, cracking, and latent heat due to thermal pressurization and melting, is another important source characteristic for the energy budget of earthquake ruptures [e.g., Kanamori and Heaton, 2000; Abercrombie and Rice, 2005; Rice, 2006; Kanamori and Rivera, 2006]. The available potential 

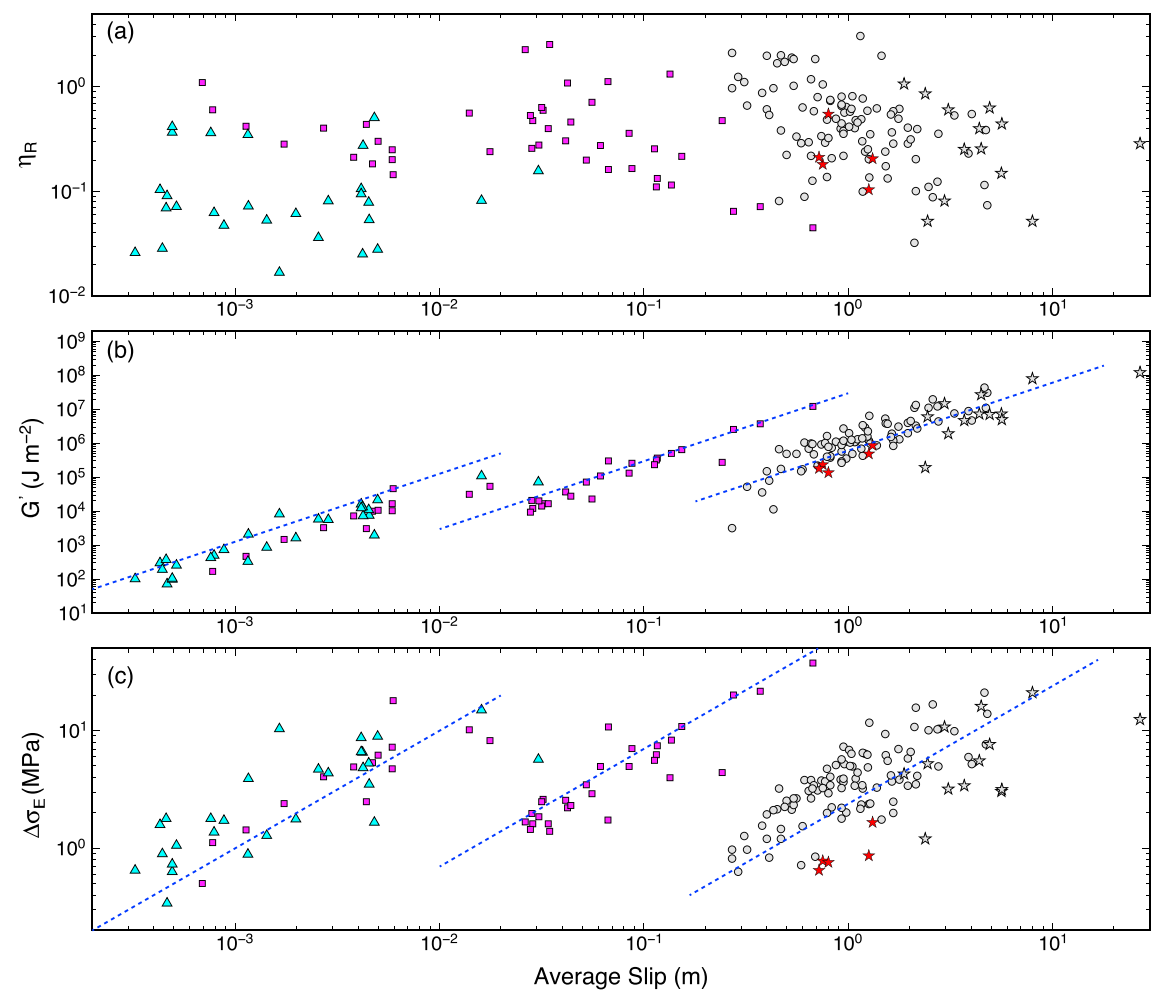

Figure 12. (a) Radiation efficiency, (b) fracture energy, and (c) energy-related stress drop $\Delta \sigma_{E}$, derived from the source parameters from the finite fault models for both group 1 (stars) and group 2 events (circles, $V_{r}=2.5 \mathrm{~km} / \mathrm{s}$ ), versus the average slip, calculated from the finite fault models for the area with trimming factors from Figure 10a. Cyan triangles (mainly Cajon Pass observations) and purple boxes (mainly Northridge aftershocks and Long Valley events) are values from Abercrombie and Rice [2005]. Tsunami earthquakes are highlighted with red stars. The blue dashed lines in Figures $11 \mathrm{~b}$ and $11 \mathrm{c}$ show the linear trends with slopes of 2 and 1, respectively, in log-log scale.

energy $\Delta W_{0}$ (which excludes the frictional energy associated with work done against the resistance to sliding on the fault plane) is equal to the radiated seismic energy plus the total fracture energy for rupture with total surface area $A$ :

$$
\Delta W_{0}=E_{R}+G A
$$

Rewriting this to express $G$ in terms of $E_{R}$ and $\eta_{R}$ gives:

$$
G=E_{R}\left(\eta_{R}^{-1}-1\right) / A .
$$

Using equation (9) and our estimates of radiated energy, radiation efficiency, and effective rupture area, we can estimate $G$ (we denote these estimates as $G^{\prime}$ ) or from the equivalent expression for the proxy for fracture energy used by Abercrombie and Rice [2005]:

$$
G^{\prime}=0.5\left(\Delta \sigma-2 \mu E_{R} / M_{0}\right) D=0.5\left(1-\eta_{R}\right) \Delta \sigma D .
$$

$G$ is equal to $G$ if the final stress is equal to the final dynamic stress (i.e., there is no stress undershoot or overshoot).

Various mechanisms could cause $G^{\prime} / D$ to vary with earthquake size or total slip [e.g., Rice, 2006]. Variation in $G^{\prime}$ could result from $\eta_{R}$ varying with event size or total slip. Abercrombie and Rice [2005] and Rice [2006] inferred variation of $G^{\prime}$ with slip for a data set they compiled. We show the $G^{\prime}$ values computed for our data set in Figure 12b together with those compiled by Abercrombie and Rice [2005]. Our major and great earthquake population extends the overall trend of $G^{\prime}$ with slip displayed by Abercrombie and Rice [2005] and Rice [2006], and our observations overlap the averaged results for large events they show (those values have been omitted here). The $G^{\prime}$ values computed for the events with nominal values of $\eta_{R}>1$ become negative. This is obviously an artifact arising from the nonphysical $\eta_{R}(>1$ ), and we omit those events (18 from our major event 
Table 2. Stress Drop and Radiation Efficiency Averages

\begin{tabular}{|c|c|c|c|c|c|c|c|c|c|c|}
\hline & \multicolumn{4}{|c|}{ Group 1 Earthquakes } & \multicolumn{6}{|c|}{ Group 2 Earthquakes } \\
\hline & \multicolumn{2}{|c|}{5 Tsunami EQ. } & \multicolumn{2}{|c|}{13 Others EQ. } & \multicolumn{2}{|c|}{$V_{r}=2.0 \mathrm{~km} / \mathrm{s}$} & \multicolumn{2}{|c|}{$V_{r}=2.5 \mathrm{~km} / \mathrm{s}$} & \multicolumn{2}{|c|}{$V_{r}=3.0 \mathrm{~km} / \mathrm{s}$} \\
\hline & $\Delta \sigma_{E}(\mathrm{MPa})$ & $\eta_{R}$ & $\Delta \sigma_{E}(\mathrm{MPa})$ & $\eta_{R}$ & $\Delta \sigma_{E}(\mathrm{MPa})$ & $\eta_{R}$ & $\Delta \sigma_{E}(\mathrm{MPa})$ & $\eta_{R}$ & $\Delta \sigma_{E}(\mathrm{MPa})$ & $\eta_{R}$ \\
\hline Geometric average & 0.89 & 0.21 & 5.61 & 0.27 & 7.00 & 0.21 & 3.45 & 0.43 & 1.99 & 0.71 \\
\hline Arithmetic average & 0.94 & 0.25 & 7.47 & 0.39 & 9.07 & 0.30 & 4.44 & 0.62 & 2.53 & 1.01 \\
\hline
\end{tabular}

set and 6 from the smaller events) in Figure 12b. However, omission of these events does not affect the overall trend defined by the remaining events. The cause of the baseline shifts apparent in the segmented trends is not clear, but the data show similar slopes close to 2 in each segment population due to correlation of $\Delta \sigma$ and $D$ (Figure 12c), for a moderate range of $\eta_{R}$ in equation (7). The baseline shifts (reproduced from the previous papers) could be due to comparison of events in different environments, differences in measurement procedures, and differences in material parameters. Thermal weakening models predict some downward curvature of the $\log G^{\prime}-\log D$ relations [Rice, 2006], but our data for large slip values do not exhibit such a trend. Further work to understand the segmentation of these measurements, to account for the negative $G^{\prime}$ estimates, and to reduce uncertainty in the measurements appears to be necessary before drawing firm conclusions about thermal weakening or other slip dependent processes.

\section{Discussion and Conclusions}

As we discussed earlier, the most difficult kinematic parameter to constrain with slip inversion of only teleseismic data is the rupture speed, $V_{r}$. Thus, we consider a range from $V_{r}=2.0 \mathrm{~km} / \mathrm{s}$ to $3.0 \mathrm{~km} / \mathrm{s}$ and use the model with $V_{r}=2.5 \mathrm{~km} / \mathrm{s}$ as a reference model. The rupture speed of individual events can vary over an even wider range, but we believe that a reference speed $2.5 \mathrm{~km} / \mathrm{s}$ is a reasonable average for group 2 events for the following reason. As shown in Table 2, the geometrical average of $\Delta \sigma_{E}$ is 0.89 for five tsunami earthquakes and 5.61 for the other 13 group 1 earthquakes. For these events, the rupture speed is independently constrained. In Table 2 we show the geometrical average of $\Delta \sigma_{E}$ and $\eta_{R}$ computed with $V_{r}=2.0 \mathrm{~km} / \mathrm{s}, 2.5 \mathrm{~km} / \mathrm{s}$, and $3.0 \mathrm{~km} / \mathrm{s}$ for all group 2 events. Although there may be some small tsunami earthquake-like events (e.g., 2012 El Salvador event) in group 2, most events are deeper on their megathrust. The values of $\Delta \sigma_{E}$ for $V_{r}=2.0$ and $3.0 \mathrm{~km} / \mathrm{s}$ bracket the average $\Delta \sigma_{E}$ of the 13 nontsunami earthquakes listed in Table 2. Thus, we believe that $V_{r} \sim 2.5 \mathrm{~km} / \mathrm{s}$ is a reasonable average rupture speed for group 2 events. The same argument can be made for $\eta_{R}$, and for the arithmetic average of $\Delta \sigma_{E}$, and $\eta_{R}$. Also, as shown in the previous section, $V_{r}=2.5 \mathrm{~km} / \mathrm{s}$ gives a $A_{\text {eff }}$ versus $M_{0}$ relation that is consistent with the previous studies.

Extensive efforts have been made over recent decades to obtain constraints on earthquake physics from seismically measurable parameters. Much of this has focused on establishing scaling relationships between small and large earthquakes and characterization of stress heterogeneity on faults. Our catalog of finite-fault solutions, rupture durations, static stress drops, and radiated energy estimates for $114 M_{w} \geq 7$ interplate megathrust events from 1990 to 2015 continues this process of accumulation of observational constraints on earthquake ruptures. The essential data are global broadband seismic wave recordings that are processed by relatively uniform procedures intended to recover first-order parameters of the large magnitude events, extending prior systematic point source treatment of smaller events. We are very cognizant of the assumptions, limitations, and uncertainties of the parameter estimation and proceed with limited consideration of some implications of the kinematic parameters for earthquake dynamic processes.

Scaling relations of earthquake rupture characteristics for these major and great subduction zone megathrust earthquakes have been explored. The source duration, moment-scaled radiated energy, apparent stress, and radiation efficiency estimates generally follow expected self-similarity relationships overall, albeit with large variability, extending previous studies to the large magnitude range. The energy-related stress drop, $\Delta \sigma_{E}$, calculated from inverted finite-fault slip models, averages $\sim 4 \mathrm{MPa}$, with there being a direct trade-off between assumed $V_{r}$ and estimated stress drop for individual events, but little overall dependence on earthquake magnitude. By performing a series of finite-fault inversions with assumed rupture velocities of $2 \mathrm{~km} / \mathrm{s}$, $2.5 \mathrm{~km} / \mathrm{s}$, and $3 \mathrm{~km} / \mathrm{s}$, the product $V_{r}^{3} \Delta \sigma_{E}$, is found to be very stable for each event over the suite of models, 
and this product has little trend with $M_{w}$, although there is a baseline shift to low values for large tsunami earthquakes. By investigating $V_{r}^{3} \Delta \sigma_{E}, \mathrm{~T}_{\mathrm{c}} \sim M_{0}{ }^{1 / 3}$, trimming factor, and assumptions of variable radiation efficiency, uniform rupture geometry parameters, or variable stress drop, we have examined observations and predictions of stress drop, effective rupture area and rupture velocity measurements. Using simple scaling assumptions can help to highlight unusual events, but full finite-source analysis is required to account for the combined variability in geometrical factors, stress drop, and radiated energy for very large earthquakes. In contrast to the increasing trends observed for small earthquakes in previous studies, radiation efficiency tends to decrease with average slip for major interplate events and estimates of fracture energy increase steadily with slip. Further work to understand the possible discrepancy between small and major/great earthquake measurements is necessary before drawing conclusions on the responsible mechanical process.

\section{Acknowledgments}

This work made use of GMT and SAC software. We appreciate comments in the manuscript by the Associate Editor, Rachel Abercrombie, Gavin Hayes, Kazuk Koketsu, and an anonymous reviewer that improved this presentation. The Incorporated Research Institutions for Seismology data management center was used to access the seismic data from Global Seismic Network and Federation of Digital Seismic Network stations. This work was supported by U.S. National Science Foundation grant EAR1245717 (T.L.). Digital information about the moment rate functions and finite-fault slip models for all events can be found at https://sites.google. com/site/linglingye001/earthquakes/ slip-models.

\section{References}

Abercrombie, R. E. (1995), Earthquake source scaling relationships from-1 to $5 \mathrm{ML}$ using seismograms recorded at 2.5-km depth, J. Geophys. Res., 100(B2), 24,015-24,036, doi:10.1029/95JB02397.

Abercrombie, R. E., and J. R. Rice (2005), Can observations of earthquake scaling constrain slip weakening?, Geophys. J. Int., 162(2), 406-424. Aki, K. (1967), Scaling law of seismic spectrum, J. Geophys. Res., 72(4), 1217-1231, doi:10.1029/JZ072i004p01217.

Allmann, B. P., and P. M. Shearer (2009), Global variations of stress drop for moderate to large earthquakes, J. Geophys. Res., 114, B01310, doi:10.1029/2008JB005821.

Baltay, A. S., G. C. Beroza, and S. Ide (2014), Radiated energy of great earthquakes from teleseismic empirical Green's function deconvolution, Pure Appl. Geophys., doi:10.1007/s00024-014-0804-0.

Baltay, A., S. Ide, G. Prieto, and G. C. Beroza (2011), Variability in earthquake stress drop and apparent stress, Geophys. Res. Lett., 38, L06303, doi:10.1029/2011GL046698.

Bassin, C., G. Laske, and G. Masters (2000), The current limits of resolution for surface wave tomography in North America, EOS. Trans.. AGU, 81, F897.

Bilek, S., and T. Lay (2000), Depth dependent rupture properties in circum-Pacific subduction zones, in GeoComplexity and the Physics of Earthquakes, Geophys. Monogr., vol. 120, pp. 165-186, AGU, Washington, D. C.

Bouchon, M. (1981), A simple method to calculate Green's functions for elastic layered media, Bull. Seismol. Soc. Am., 71(4), 959-971.

Brune, J. (1970), Tectonic stress and the spectra of seismic shear waves from earthquakes, J. Geophys. Res., 75, 4997-5009, doi:10.1029/ JB075i026p04997.

Choy, G. L., A. McGarr, S. H. Kirby, and J. Boatwright (2006), An overview of the global variability in radiated energy and apparent stress, in Earthquakes: Radiated Energy and the Physics of Faulting, Geophys. Monogr. Ser., vol. 170, pp. 43-57, AGU, Washington, D. C., doi:10.1029/170GM01.

Convers, J. A., and A. V. Newman (2011), Global evaluation of large earthquake energy from 1997 through mid-2010, J. Geophys. Res., 116, B08304, doi:10.1029/2010JB007928.

Dahlen, F. A. (1977), The balance of energy in earthquake faulting, Geophys. J. Int., 48(2), $239-261$.

Duputel, Z., V. C. Tsai, L. Rivera, and H. Kanamori (2013), Using centroid time-delays to characterize source durations and identify earthquakes with unique characteristics, Earth Planet. Sci. Lett., 375, 92-100, doi:10.1016/j.epsl.2013.05.024.

Dziewonski, A. M., and J. H. Woodhouse (1983), An experiment in systematic study of global seismicity: Centroid-moment tensor solutions for 201 moderate and large earthquakes of 1981, J. Geophys. Res., 88(B4), 3247-3271, doi:10.1029/JB088iB04p03247.

Gallovič, F., W. Imperatori, and P. M. Mai (2015), Effects of three-dimensional crustal structure and smoothing constraint on earthquake slip inversions: Case study of the Mw6.3 2009 L'Aquila earthquake, J. Geophys. Res. Solid Earth, 120, 428-449, doi:10.1002/2014JB011650.

Geist, E. L., and T. Parsons (2005), Triggering of tsunamigenic aftershocks from large strike-slip earthquakes: Analysis of the November 2000 New Ireland earthquake sequence, Geochem. Geophys. Geosyst., 6, Q10005, doi:10.1029/2005GC000935.

Hartzell, S. H., and T. H. Heaton (1983), Inversion of strong ground motion and teleseismic waveform data for the fault rupture history of the 1979 Imperial Valley, California, earthquake, Bull. Seismol. Soc. Am., 73(6A), 1553-1583.

Ide, S. (2002), Estimation of radiated energy of finite-source earthquake models, Bull. Seismol. Soc. Am., 92(8), $2994-3005$.

Ide, S., and G. C. Beroza (2001), Does apparent stress vary with earthquake size?, Geophys. Res. Lett., 28, 3349-3352, doi:10.1029/2001GL013106.

Ide, S., G. C. Beroza, S. G. Prejean, and W. L. Ellsworth (2003), Apparent break in earthquake scaling due to path and site effects on deep borehole recordings, J. Geophys. Res., 108(B5), 2271, doi:10.1029/2001JB001617.

Kanamori, H. (2014), The diversity of large earthquakes and its implications for hazard mitigation, Annu. Rev. Earth Planet. Sci., 42, 7-26, doi:10.1146/annurev-earth-060313-055034.

Kanamori, H., and D. L. Anderson (1975), Theoretical basis of some empirical relations in seismology, Bull. Seismol. Soc. Am., 65, $1073-1095$.

Kanamori, H., and T. H. Heaton (2000), Microscopic and macroscopic physics of earthquakes, in GeoComplexity and the Physics of Earthquakes, Geophys. Monogr., vol. 120, pp. 147-163, AGU, Washington, D. C.

Kanamori, H., and L. Rivera (2006), Energy partitioning during and earthquake, in Earthquakes: Radiated Energy and the Physics of Faulting, Geophys. Monogr. Ser. vol. 170, pp. 3-13, AGU, Washington, D. C., doi:10.1029/170GM03.

Kanamori, H., E. Hauksson, L. K. Hutton, and L. M. Jones (1993), Determination of earthquake energy release and ML using TERRAscope, Bull. Seismol. Soc. Am., 83, 330-346.

Kanamori, H., D. L. Anderson, and T. H. Heaton (1998), Frictional melting during the rupture of the 1994 Bolivian earthquake, Science, 279 , 839-842, doi:10.1126/science.279.5352.839.

Kikuchi, M., and H. Kanamori (1991), Inversion of complex body waves-III, Bull. Seismol. Soc. Am., 81(6), 2335-2350.

Kostrov, B. V. (1973), Seismic moment, earthquake energy and seismic flow of rocks, Publ. Inst. Geophys. Pol. Acad. Sci, 62, $25-47$.

Lay, T. (2015), The surge of great earthquakes from 2004 to 2014, Earth Planet. Sci. Lett., 409, 133-146.

Lay, T., C. J. Ammon, A. R. Hutko, and H. Kanamori (2010), Effects of kinematic constraints on teleseismic finite-source rupture inversions: Great Peruvian earthquakes of 23 June 2001 and 15 August 2007, Bull. Seismol. Soc. Am., 100, 969-994, doi:10.1785/0120090274.

Lay, T., H. Kanamori, C. J. Ammon, K. D. Koper, A. R. Hutko, L. Ye, H. Yue, and T. Rushing (2012), Depth-varying rupture properties of subduction zone megathrust faults, J. Geophys. Res., 117, B04311, doi:10.1029/2011JB009133. 
Lay, T., L. Ye, H. Kanamori, Y. Yamazaki, K. F. Cheung, and C. J. Ammon (2013a), The February 6, 2013 M 8.0 Santa Cruz Islands earthquake and tsunami, Tectonophysics, 608, 1109-1121, doi:10.1016/j.tecto.2013.07.001.

Lay, T., L. Ye, H. Kanamori, Y. Yamazaki, K. F. Cheung, K. D. Koper, and K. Kwong (2013b), The October 28, 2012 Mw 7.8 Haida Gwaii underthrusting earthquake and tsunami: Slip partitioning along the Queen Charlotte Fault transpressional plate boundary, Earth Planet. Sci. Lett., 375, 57-70, doi:10.1016/j.epsl.2013.05.005.

Madariaga, R. (1976), Dynamics of an expanding circular fault, Bull. Seismol. Soc. Am., 66, 639-666.

Mansinha, L., and D. E. Smylie (1971), The displacement fields of inclined faults, Bull. Seismol. Soc. Am., 61(5), $1433-1440$.

McGarr, A. (1999), On relating apparent stress to the stress causing earthquake fault slip, J. Geophys. Res., 104(B2), 3003-3011, doi:10.1029/ $1998 \mathrm{JB} 900083$.

Newman, A. V., and E. A. Okal (1998), Teleseismic estimates of radiated seismic energy: The $E / M_{0}$ discriminant for tsunami earthquakes, J. Geophys. Res., 103, 26,885-26,898, doi:10.1029/98JB02236.

Noda, H., N. Lapusta, and H. Kanamori (2013), Comparison of average stress drop measures for ruptures with heterogeneous stress change and implications for earthquake physics, Geophys. J. Int., 193(3), 1691-1712, doi:10.1093/gji/ggt074.

Ohnaka, M. (2003), A constitutive scaling law and a unified comprehension for frictional slip failure, shear fracture of intact rock, and earthquake rupture. J. Geophys. Res., 108(B2), 2080, doi:10.1029/2000JB000123.

Okada, Y. (1992), Internal deformation due to shear and tensile faults in a half-space, Bull. Seismol. Soc. Am., 82(2), 1018-1040.

Pérez-Campos, X., and G. C. Beroza (2001), An apparent mechanism dependence of radiated seismic energy, J. Geophys. Res., 106(B6), 11,127-11,136, doi:10.1029/2000JB900455.

Polet, J., and H. Kanamori (2009), Tsunami earthquakes, in Encyclopedia of Complexity and Systems Science, pp. 9577-9592, Springer, New York.

Prieto, G. A., D. J. Thomson, F. L. Vernon, P. M. Shearer, and R. L. Parker (2007), Confidence intervals for earthquake source parameters, Geophys. J. Int., 168(3), 1227-1234.

Rice, J. R. (2006), Heating and weakening of faults during earthquake slip, J. Geophys. Res., 111, B05311, doi:10.1029/02005JB004006.

Rivera, L., and H. Kanamori (2005), Representations of the radiated energy in earthquakes, Geophys. J. Int., 162(1), $148-155$.

Rivera, L., and H. Kanamori (2014), Estimation of radiated energy of recent great earthquakes using the normal-mode theory, Abstract S53B-4502 presented at 2014 Fall Meeting, AGU, San Francisco, Calif.

Shearer, P. M., G. A. Prieto, and E. Hauksson (2006), Comprehensive analysis of earthquake source spectra in southern California, J. Geophys. Res., 111, B06303, doi:10.1029/2005JB003979.

Venkataraman, A., and H. Kanamori (2004), Observational constraints on the fracture energy of subduction zone earthquakes, J. Geophys. Res., 109, B05302, doi:10.1029/2003JB002549.

Walter, W. R., K. Mayeda, R. Gok and A. Hofstetter (2006), The scaling of seismic energy with moment: Simple models compared with observations, in Earthquakes: Radiated Energy and the Physics of Faulting, edited by R. Abercrombie, et al., AGU, Washington, D. C., doi:10.1029/170GM05.

Wells, D. L., and K. J. Coppersmith (1994), New empirical relationships among magnitude, rupture length, rupture width, rupture area, and surface displacement, Bull. Seismol. Soc. Am., 84(4), 974-1002.

Wyss, M. (1970), Stress estimates for South American shallow and deep earthquakes, J. Geophys. Res., 75, $1529-1554$.

Ye, L., T. Lay, and H. Kanamori (2013a), Ground shaking and seismic source spectra for large earthquakes around the megathrust fault offshore of northeastern Honshu, Japan, Bull. Seismol. Soc. Am., 103(2B), 1221-1241, doi:10.1785/0120120115.

Ye, L., T. Lay, and H. Kanamori (2013b), Large earthquake rupture process variations on the Middle America megathrust, Earth Planet. Sci. Lett., 381, 147-155.

Ye, L., T. Lay, H. Kanamori, and K. D. Koper (2013c), Energy release of the $2013 M_{w} 8.3$ Sea of Okhotsk earthquake and deep slab stress heterogeneity, Science, 341, 1380-1384.

Ye, L., T. Lay, H. Kanamori, and L. Rivera (2016), Rupture characteristics of major and great $\left(\mathrm{M}_{\mathrm{w}} \geq 7\right)$ megathrust earthquakes from 1990 to 2015: 2. Depth dependence, J. Geophys. Res. Solid Earth, 121, 845-863, doi:10.1002/2015JB012427. 